\title{
Construction of Microunits by Adipose-Derived Mesenchymal Stem Cells Laden with Porous Microcryogels for Repairing an Acute Achilles Tendon Rupture in a Rat Model
}

This article was published in the following Dove Press journal:

International Journal of Nanomedicine

Xuan Yang $\mathbb{D}^{1,2}$
Haoye Meng'
Jiang Peng'
Lijuan Xu'
Yu Wang'
Xun Sun $\mathbb{D}^{3}$
Yanxu Zhao'
Qi Quan'
Wen Yu'
Mingxue Chen'
Tong Shi'
Yanan Du
${ }^{4}$
Shibi Lu'
Aiyuan Wang

'Department of Orthopedic Surgery, Key Laboratory of Musculoskeletal Trauma \&war Injuries PLA, Beijing Key Laboratory of Regenerative Medicine in Orthopedics, Chinese PLA General Hospital, Beijing I00853, People's Republic of China; ${ }^{2}$ Department of orthopedics, The First Hospital of Shanxi Medical University YanHu District Branch, Yuncheng, Shanxi 044000, People's Republic of China; ${ }^{3}$ Department of Orthopedics, Tianjin Hospital, Tianjin 3002 II, People's Republic of China; ${ }^{4}$ Department of Biomedical Engineering, School of Medicine, Tsinghua University, Beijing 100084, People's Republic of China

Correspondence: Aiyuan Wang; Jiang Peng

Email aiyuanwang30I@I26.com; pengjiang30I@I26.com
Objective: Tissue engineering approaches seem to be an attractive therapy for tendon rupture. Novel injectable porous gelatin microcryogels (GMs) can promote cell attachment and proliferation, thus facilitating the repair potential for target tissue regeneration. The research objectives of this study were to assess the efficacy of tissue-like microunits constructed by multiple GMs laden with adipose-derived mesenchymal stem cells (ASCs) in accelerated tendon regeneration in a rat model.

Methods: Through a series of experiments, such as isolation and identification of ASCs, scanning electron microscopy, mercury intrusion porosimetry (MIP), laser scanning confocal microscopy and the CCK-8 test, the biocompatibility of GMs was evaluated. In an in vivo study, 64 rat right transected Achilles tendons were randomly divided into four groups: the ASCs+GMs group (microunits aggregated by multiple ASC-laden GMs injected into the gap), the ASCs group (ASCs injected into the gap), the GMs group (GMs injected into the gap) and the blank defect group (non-treated). At 2 and 4 weeks postoperatively, the healing tissue was harvested to evaluate the gross observation and scoring, biomechanical testing, histological staining and quantitative scoring. Gait analysis was performed over time. The 64 rats were randomly assigned into 4 groups: (1) micro-unit group (ASCs+GMs) containing ASC $\left(10^{5}\right)$-loaded $120 \mathrm{GMs}$ in $60 \mu \mathrm{L}$ DMEM; (2) cell control group (ASCs) containing $10^{6}$ ASCs in $60 \mu \mathrm{L}$ DMEM; (3) GM control group (GMs) containing 120 blank GMs in $60 \mu \mathrm{L}$ DMEM; (4) blank defect group (Defect) containing $60 \mu \mathrm{L}$ DMEM, which were injected into the defect sites. All animals were sacrificed at 2 and 4 weeks postsurgery (Table 1).

Results: In an in vitro study, GMs (from $126 \mu \mathrm{m}$ to $348 \mu \mathrm{m}$ ) showed good porosities and a three-dimensional void structure with a good interpore connectivity of the micropores and exhibited excellent biocompatibility with ASCs. As the culture time elapsed, the extracellular matrix (ECM) secreted by ASCs encased the GMs, bound multiple microspheres together, and then formed active tendon tissue-engineering microunits. In animal experiments, the ASCs+GMs group and the ASCs group showed stimulatory effects on Achilles tendon healing. Moreover, the ASCs+GMs group was the best at improving the macroscopic appearance, histological morphology, Achilles functional index (AFI), and biomechanical properties of repair tissue without causing adverse immune reactions.

Conclusion: Porous GMs were conducive to promoting cell proliferation and facilitating ECM secretion. The ASCs-GMs matrices showed an obvious therapeutic efficiency for Achilles tendon rupture in rats.

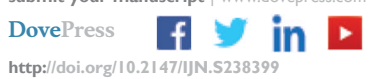

International Journal of Nanomedicine 2020:|5 7|55-7|7|

7155

(c) (5) ( 2020 Yang et al. This work is published and licensed by Dove Medical Press Limited. The full terms of this license are available at https://www.dovepress.com/terms.php (c) ${ }_{\mathrm{BY}} \mathrm{NC}$ and incorporate the Creative Commons Attribution - Non Commercial (unported, v3.0) License (http://creativecommons.org/licenses/lby-nc/3.0/). By accessing the work you hereby accept the Terms. Non-commercial uses of the work are permitted without any further permission from Dove Medical Press Limited, provided the work is properly attributed. For permission for commercial use of this work, please see paragraphs 4.2 and 5 of our Terms (https://www.dovepress.com/terms.php). 
Keywords: Achilles tendon rupture, tendon tissue engineering, adipose-derived mesenchymal stem cells, ASCs, injectable biomaterials

\section{Introduction}

The Achilles tendon is the largest and strongest tendon in the human body and begins from the extension of the calf triceps and ends with the calcaneus. The incidence of ruptured Achilles tendon has continued to rise over the past decade. ${ }^{1,2}$ Apart from direct trauma, more than $70 \%$ of the Achilles tendon ruptures are related to increased participation in sports, particularly ball games and other athletics. ${ }^{3}$ Additional factors, including gender, age, corticosteroids and microtrauma, may all contribute. ${ }^{1,4-6}$ There still exists controversy regarding the best treatment for the Achilles tendon. The numerous treatments described in published studies are mainly divided into two methods: surgical and nonsurgical. Surgical management mainly consists of open repair, percutaneous repair and limited open repair, while nonsurgical methods involve strict immobilization and subsequently functional rehabilitation in a cast or brace. ${ }^{7-10}$ Both limited open repair and conservative management are viable alternatives due to reported advantages such as similar rerupture rates, lower overall complication rates, satisfactory outcomes and a better cosmetic appearance when compared with traditional open repair. ${ }^{11}$ However, these tendon repair methods result in healed tissue with poor mechanical and functional qualities.

Nonetheless, tendon engineering provides a promising approach for repairing Achilles tendon rupture. Recently, many animal models have demonstrated that Achilles tendon healing can be accelerated by methods such as local injection of biologics, transplanting biomaterials combined with cells and gene therapy. ${ }^{12-15}$ Notably, local injection of bone marrow cells has been reported to accelerate Achilles tendon healing in rat models. ${ }^{12}$ Obviously, minimally invasive therapeutic approaches, such as injections enable reducing wound-related complications and increasing the effectiveness of the treatment, have been recommended. At present, bone marrow-derived mesenchymal stem cells (BMSCs) and ASCs are the two most commonly used seed cells. Although BMSCs have been successfully applied in many studies, it is difficult for BMSCs to serve as cell sources because of their invasive properties. ${ }^{16}$ Compared to BMSCs, adipose-derived mesenchymal stem cells (ASCs) are advantageous for harvesting, are easier to expand, have wider sources and have lower immunogenicity. ${ }^{17-20}$ Thus, we chose ASCs as our experimental cells.

Traditional direct injection easily leads to cell loss and cell death. The high rate of cell loss due to leakage to surrounding tissues, cell death due to mechanical damage during injection, and lack of appropriate cell-cell and cellmatrix interactions due to digestive resuspension could all be relevant to the poor cell retention, survival and functionality in ischemic and inflammatory lesion tissues. ${ }^{21,22}$ To enhance cell-based regenerative therapy, biomaterial-assisted minimally invasive injectable carriers based on natural polymers are expected to ameliorate the abovementioned conditions. ${ }^{22-24}$ Previously, our groups developed injectable microscale cellular carriers, namely, biodegradable gelatin microcryogels (GMs), which provide a conductive 3D environment for stem cell attachment and proliferation and stimulate the accumulation of deposited extracellular matrix (ECM) as well as enhance cell-cell interactions. ${ }^{25}$ Porous GMs have been proven to protect cell membranes from rupture during injection and facilitate prolonged cell survival and maintain cell functionality in the harsh injury environment. ${ }^{25}$ In the present study, we aimed to investigate the compatibility between ASCs and GMs and examined the effects of injecting microunits constructed by ASCs seeded within GMs on tendon healing in a rat model of Achilles tendon rupture. The hypothesis of this study was that tendon healing could be accelerated by microunits resulting from histological and biomechanical analysis as well as functional evaluation of the Achilles tendon.

\section{Materials and Methods}

\section{Rats and Experimental Design}

A total of 80 male Sprague Dawley rats were purchased from the Laboratory Animal Center of the Academy of Military Medical Sciences of China. Sixteen of these rats were 3 days old and were used for the preparation of ASCs. The remaining 64 rats weighing $200 \mathrm{~g}$ to $220 \mathrm{~g}$ were used for animal experiments. All studies were approved by the Ethics Committee of the Animal Facility of Chinese PLA General Hospital and according to Laboratory animal-Guideline for ethical review of animal welfare (GB/T 35,892-2018).

The 64 rats were randomly assigned into 4 groups: (1) micro-unit group (ASCs $+\mathrm{GMs}$ ) containing ASCs $\left(10^{5}\right)$-loaded 
120 GMs in $60 \mu \mathrm{L}$ DMEM; (2) cell control group (ASCs) containing $10^{6}$ ASCs in $60 \mu \mathrm{L}$ DMEM; (3) GM control group (GMs) containing 120 blank GMs in $60 \mu \mathrm{L}$ DMEM; (4) blank defect group (Defect) containing $60 \mu \mathrm{L}$ DMEM, which were injected into the defect sites. All animals were sacrificed at 2 and 4 weeks postsurgery (Table 1).

\section{Preparation of GMs and Characterization of GMs}

Fabrication of GMs has been described previously. ${ }^{25}$ In brief, porous gelatin microcryogels were prepared by polymethyl methacrylate (PMMA) microstencil array chips (600 microwells with a diameter of $400 \mu \mathrm{m}$ ) fabricated by a laser prototyping technique. An adequately dissolved gelatin precursor solution [6\% (wt/vol) in deionized water] was incubated on ice for $5 \mathrm{~min}$ followed by the addition of $0.3 \%$ glutaraldehyde. Then, $200 \mu \mathrm{L}$ of premixed solution was pipetted onto the holes of the chips. The chips underwent cryogelation for $16 \mathrm{~h}$ in a $-20{ }^{\circ} \mathrm{C}$ refrigerator and were then lyophilized for $30 \mathrm{~min}$. Approximately 600 interconnected macroporous GMs could be harvested by the push-out method and then washed with $0.1 \mathrm{M} \mathrm{NaBH}_{4}$ to neutralize the uncross-linked aldehyde, followed by extensive washing with deionized water. These GMs were next harvested into a dish in the shape of a monolayer, lyophilized, and stored in vacuum for characterization analysis and cell culture.

The harvested and freeze-dried GMs were observed by a granulometer (Morphologi G3-ID) and then gold-coated for scanning electron microscope (SEM, Hitachi S-3000N) imaging. The particle size distribution of GMs was measured by mercury intrusion porosimetry (MIP) (Poremaster-GT60).

\section{Isolation and Culture of ASCs}

Inguinal fat pads from 3-day-old rats were cut into small pieces $\left(<1 \mathrm{~mm}^{3}\right)$ and digested in $1 \mathrm{mg} / \mathrm{mL}$ collagenase type II (Sigma) for $1 \mathrm{~h}$ at $37{ }^{\circ} \mathrm{C}$. The digestion was terminated with an equal volume of DMEM containing $10 \%$ FBS (fetal bovine serum, HyClone) and 1\% penicillin/streptomycin. Cells were collected after centrifugation at $201.24 \mathrm{xg}$ for $10 \mathrm{~min}$ and suspended in the expansion medium. The cell suspension was filtered through $100 \mu \mathrm{m}$ cell strainers and then centrifuged at $201.24 \mathrm{xg}$ for $5 \mathrm{~min}$. ASCs were suspended at a density of $2 \times 10^{5} / \mathrm{cm}^{3}$ with the expansion medium and cultured at $37{ }^{\circ} \mathrm{C}, 5 \% \mathrm{CO}_{2}$. Cells were passaged every 2 or 3 days when the confluence reached approximately $90 \%$ with $0.25 \%$ trypsin EDTA (Gibco). ASCs at passage 2 to passage 4 were used for the following experiments.

\section{Identification of ASCs}

Passage 2 ASCs were used to induce differentiation into adipogenic, chondrogenic and osteogenic lineages according to the corresponding reagent instructions (Cyagen). After induction, the cells were fixed in $4 \%$ paraformaldehyde at room temperature for $20 \mathrm{~min}$, washed three times in PBS and stained by oil red $\mathrm{O}$, alcian blue and alizarin red.

Surface markers were detected by flow cytometry (BECTON DICKINSON). Passage 2 ASCs were resuspended in an appropriate volume of PBS and divided into four tubes at a concentration of $10^{6}$ cells $/ \mathrm{mL}$. Then,

Table I Experimental Groups, Scaffold Components and Number of Samples Taken from Each Group Used for Each Assay

\begin{tabular}{|l|l|l|l|l|l|l|}
\hline Groups & Description & $\begin{array}{l}\text { Injection } \\
\text { Components }\end{array}$ & $\begin{array}{l}\text { Number } \\
\text { of } \\
\text { Animals }\end{array}$ & $\begin{array}{l}\text { 3D Intensity Footprints } \\
\text { Achilles Functional Index (AFI) }\end{array}$ & $\begin{array}{l}\text { Histological } \\
\text { Analysis }\end{array}$ & $\begin{array}{l}\text { Biomechanical } \\
\text { Testing }\end{array}$ \\
\hline $\begin{array}{l}\text { ASCs } \\
+ \text { GMs }\end{array}$ & $\begin{array}{l}\text { ASCs and } \\
\text { GMs }\end{array}$ & $\begin{array}{l}\text { ASCs }\left(10^{5} \text { )-loaded I } 20\right. \\
\text { GMs in } 60 \mu \mathrm{L} \text { DMEM }\end{array}$ & 16 & $4^{\mathrm{b}}$ & $3^{\mathrm{c}}$ & 5 \\
\hline ASCs & Cell control & $\begin{array}{l}10^{6} \text { ASCs in } 60-\mu \mathrm{L} \\
\text { DMEM }\end{array}$ & 16 & $4^{\mathrm{b}}$ & $3^{\mathrm{c}}$ & 5 \\
\hline GMs & GM control & $\begin{array}{l}120 \text { blank GMs in } 60-\mu \mathrm{L} \\
\text { DMEM }\end{array}$ & 16 & $4^{\mathrm{b}}$ & $3^{\mathrm{c}}$ & 5 \\
\hline Defect & Blank defect ${ }^{\mathrm{a}}$ & $60-\mu \mathrm{L}$ DMEM & 16 & $4^{\mathrm{b}}$ & $3^{\mathrm{c}}$ & 5 \\
\hline
\end{tabular}

Notes: a Complete transverse incisions was made $7 \mathrm{~mm}$ proximal to the calcaneal insertion with no surgical repair. ${ }^{\mathrm{b}} \mathrm{n}=4$ picked at random from each experimental groups at $1,4,7,10,14,21$, and 28 days. ${ }^{c} n=3$ sampled randomly from each experimental groups of eight animals at 2 weeks and 4 weeks with the remaining five samples used for biomechanical testing. 
the rat antibody (abcam) was added into the reaction for 30 min at $4{ }^{\circ} \mathrm{C}$ before testing with flow cytometry.

\section{Biocompatibility}

\section{Cell Seeding and Cell Viability and Proliferation}

After digestion and centrifugation, a concentration of $1 \times 10^{6}$ cells $/ \mathrm{mL}$ was added. Fifty microliters of the solution was slowly dropped onto a thin layer of $500 \mathrm{GMs}$ that were previously sterilized by $\mathrm{Co}^{60}$ in a $35 \mathrm{~mm}$ dish until thorough autoabsorption and incubated at $37{ }^{\circ} \mathrm{C}$ for $2 \mathrm{~h}$ to allow for cell attachment. Subsequently, the culture medium was added for long-term culture.

A CCK-8 reagent kit (CK04, Dojindo) was used to determine the cell loading capacity and proliferation within each microcryogel. First, a standard curve was created to correlate the linear relationship between fluorescence intensity and cell number. Then, GMs were seeded with different densities of ASCs, and cell viability was assessed from day 1 to day 4 . The cell number per microcryogel was calculated according to the established standard curve.

\section{Live/Dead Staining}

Fluorescein diacetate (FDA) and propidium iodide (PI) were used for live/dead staining. Briefly, at the sixth hour, the second day and the fifth day, GMs seeded with ASCs were washed three times with PBS, incubated in FDA $(5 \mu \mathrm{g} / \mathrm{mL})$ for $5 \mathrm{~min}$ at room temperature, and then washed three times in PBS and incubated in PI $(5 \mu \mathrm{g} / \mathrm{mL})$ for $5 \mathrm{~min}$. The distribution and viability of cells were observed with a laser scanning confocal microscope (TCS SP8, Leica). The viable cells showed green fluorescence, and the dead cells showed red fluorescence.

\section{SEM Assay}

GMs seeded with ASCs at $6 \mathrm{~h}, 2$ days and 4 days were examined on an SEM (Hitachi S-3000N) through a series of processes including washing in PBS, fixing in 3\% glutaraldehyde at $4{ }^{\circ} \mathrm{C}$ overnight and in $0.1 \%$ osmium acid at $4{ }^{\circ} \mathrm{C}$ for $2 \mathrm{~h}$, dehydrating in a gradient series of alcohols and final sputter-coated with gold.

\section{Surgical Protocol}

Under general anesthesia (pentobarbital), the right leg was shaved. With the use of aseptic technique, the skin followed by the paratenon was incised longitudinally over each Achilles tendon. A complete transverse incision $7 \mathrm{~mm}$ proximal to the calcaneal insertion was made with a surgical blade $(7 \mathrm{~mm})$. The skin was sutured with 4-0 monofilament nylon (Figure 1B). Next, we injected $60 \mu \mathrm{L}$ DMEM containing different abovementioned substances into the transection site. Postoperatively, both ankles were placed in casts for 12 h. Thereafter, no more immobilization was applied, and the rats were allowed to move freely in their cages to simulate early functional therapy.

\section{Macrographic Examination}

The treated rats were sacrificed under anesthesia at 2 weeks and 4 weeks after the operation. Surgical spots in the right leg were exposed to observe any signs of abnormal secretion or infection. The color and luster of the repaired tissue as well as its continuity with surrounding tissue also needed to be carefully assessed. Then, the corresponding quantitative scoring was performed according to the method in the previous paper. ${ }^{26}$

\section{D Intensity Footprints and Achilles Functional Index (AFI)}

Gait analysis was conducted on walking rats $(n=4)$ at 1,4 , $7,10,14,21$, and 28 days after the operation using the catwalk method (Catwalk XT10.6, Noldus). Achilles tendon functional recovery was quantitatively assessed using George's method, namely, the AFI, which was calculated by parameters such as the print width, print length and intermediate toe. ${ }^{27}$ The 3D intensity footprints, which reflect the pressure exerted by the paw, were measured to evaluate the tendon function of the experimental right ankles.

\section{Biomechanical Testing}

The Achilles tendon $(n=5)$ between the calcaneus and the musculotendinous junction was harvested at 2 and 4 weeks after the operation. Before testing, tendon thickness at the healing site and tendon length were measured with a precision caliper. Both ends of the specimens were securely fastened onto a mechanical testing machine (ELF3200, BOSE). The tendon was pulled at a constant speed of $0.2 \mathrm{~mm} / \mathrm{min}$. Force-displacement curves were recorded digitally for subsequent data analysis. The ultimate failure load and stiffness were measured. In five randomly chosen animals at two time points, the uninjured left Achilles tendon was also harvested for biomechanically testing, serving as the native tendon control. 

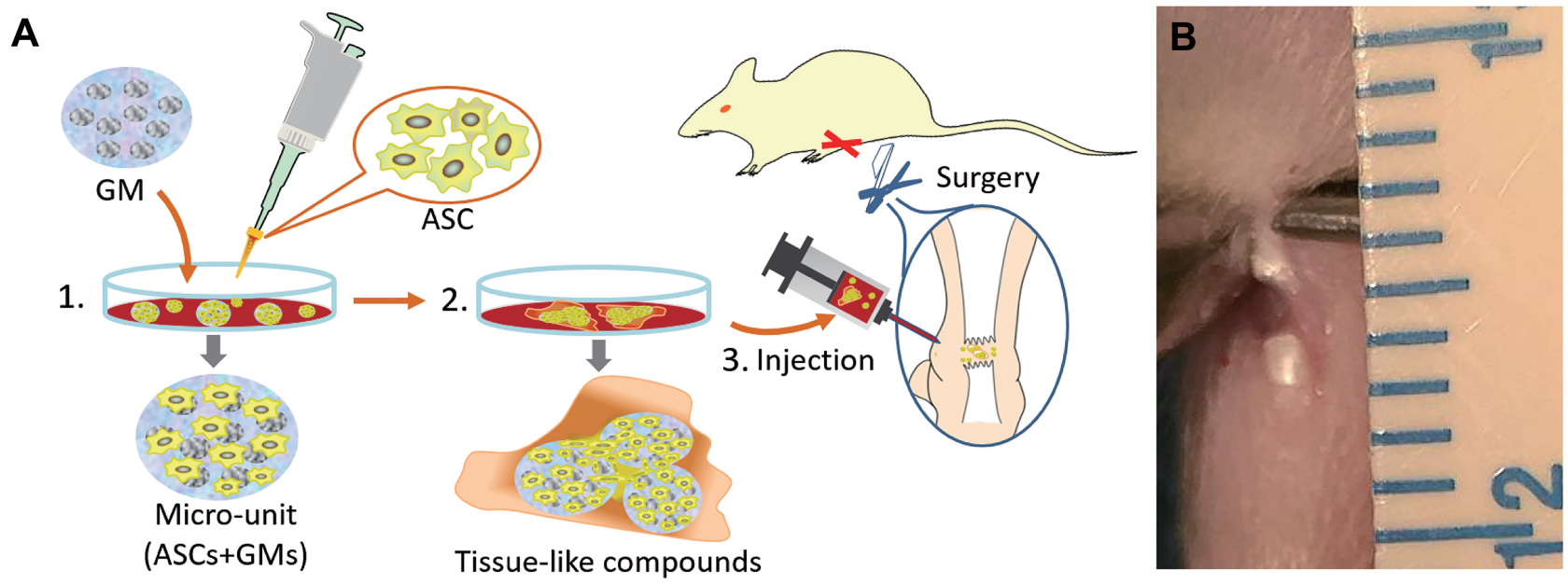

Figure I Schematic illustration of the overall research design (A). Complete transverse incision was made $7 \mathrm{~mm}$ from the calcaneal insertion of the Achilles tendon (B).

\section{Histopathological Analysis}

The harvested specimens were processed for hematoxylin and eosin (H\&E) staining, Masson staining, Sirius red staining and immunohistochemical staining. Specimens were first fixed in $4 \%$ paraformaldehyde and paraffinembedded, and then longitudinal sections $(5 \mu \mathrm{m})$ were made on the midline of the tendons' longitudinal axis. For H\&E staining, Masson staining, and Sirius red staining, sections were stained with standard protocols. For immunohistochemistry, samples were briefly processed with standard protocols such as deparaffinized, heatinduced antigen retrieval, hydrogen peroxide blocking and 5\% goat-serum occlusion and then incubated with anti-collagen type I (7 $\mu \mathrm{g} / \mathrm{mL}$, ab34710, Abcam), anticollagen type III (1:600, ab6310, Abcam) antibodies at 4 ${ }^{\circ} \mathrm{C}$ overnight. Subsequently, secondary antibody and 3,3-diaminobenzidine tetrahydrochloride (DAB) were performed according to the manufacturer's instructions. Hematoxylin was used as a nuclear counterstain. All stained sections were scanned and analyzed with light microscopy (BX-51, Olympus).

Histological scoring analysis was performed with a previously reported grading scale. ${ }^{13}$ The scale consists of the following 6 features, each quantified as $0,1,2$ or 3 : (1) fiber arrangement, (2) fiber structure, (3) angiogenesis, (4) nuclear rounding, (5) inflammation, and (6) cell density. Each slide from three randomly selected individual samples from each group at the two time points was examined by three histologists.

\section{Statistical Analysis}

Data are presented as the mean and standard deviation. For the analyses of cell viability and proliferation, Student's $t$-test was conducted. One-way ANOVA was performed in the macrographic quantitative scoring, AFI, biomechanical testing and histological scoring. For multiple comparisons, Tukey's test was used to evaluate the difference between the four groups. The Dunnett test was used between each group and the normal tendon. The significance for all statistical analyses was defined as $\mathrm{P}<0.05$. All statistical analyses were performed using SPSS 19.0.

\section{Results}

\section{Characterization of GMs}

The harvested GMs exhibited a predefined sphere or drop shape with an appropriate size (Figure 2A and C). SEM revealed that GMs had a well-distributed macroporous structure (Figure 2B and D). MIP showed that the diameters of GMs ranged from $126 \mu \mathrm{m}$ to $348 \mu \mathrm{m}$, with a mean pore size of $47.38 \mu \mathrm{m}$ and a high porosity of 90.18\% (Figure 2E). Moreover, long-term preservation of the collected GMs was realized by vacuum packaging.

\section{Phenotypic Characterization and Multiple Differentiation of ASCs}

The number of ASCs presented a long spindle shape, and a few were polygonal and round from P0 to P3. After culture for 3 days, ASCs exhibited mass proliferation with a spiral growth habit. The results of surface markers 
A

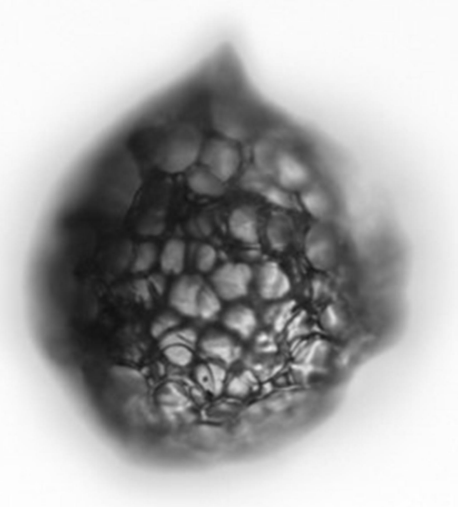

C

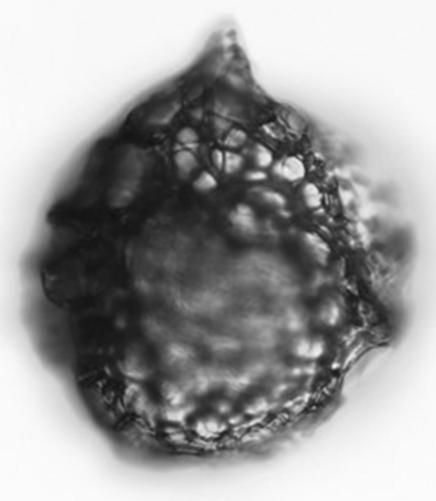

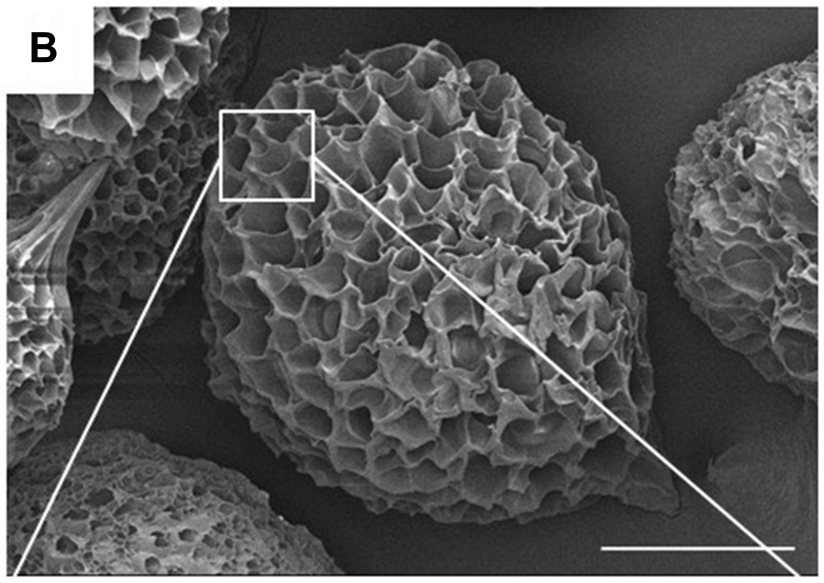

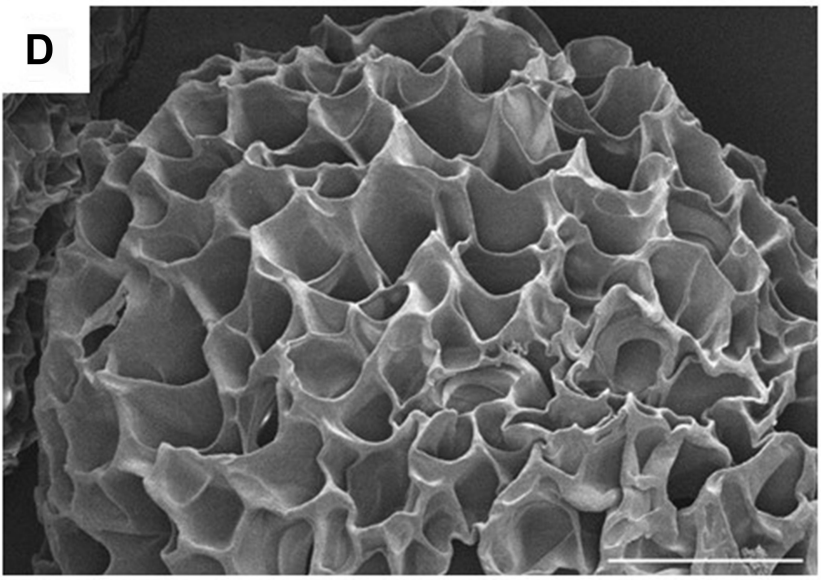

E

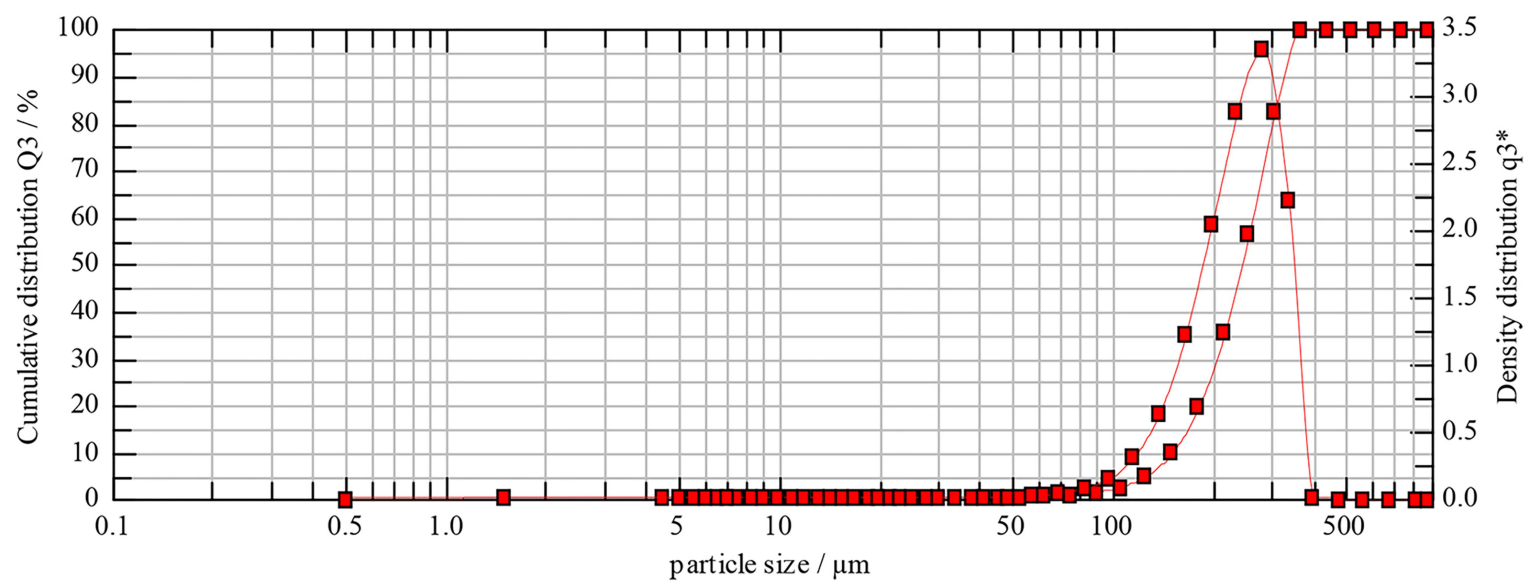

Figure 2 Observation of GMs by granulometry $(\mathbf{A}, \mathbf{C})$ and scanning electron microscopy (B, D). Report of GMs size distribution by mercury intrusion porosimetry (E). The white rectangle indicates the area shown in the below images at higher magnification. Scale bars: $50 \mu \mathrm{m}$ in $A, 20 \mu \mathrm{m}$ in $C, 100 \mu \mathrm{m}$ in $B$ and $50 \mu \mathrm{m}$ in $\mathrm{D}$.

of ASCs showed stem cell-associated markers CD90 and CD29 with no expression of CD34 and CD45 (Figure 3A).

After induction of osteogenesis for 15 days, the cells grew in layers and nodules with obvious calcium deposition nodules and positive alizarin red staining (Figure 3C). After 10 days of adipocytic induction, oval lipid droplets were observed in most of the ASCs under a microscope with positive oil red $\mathrm{O}$ staining (Figure 3D). After 3 weeks of chondrogenic differentiation, the cells agglomerated and integrated into a pellet, which could be stained with alcian blue (Figure 3B).

\section{Biocompatibility of ASCs Seeded Within GMs}

ASCs cultured in GMs had a significantly elevated proliferation rate compared with that of single ASC cultures 

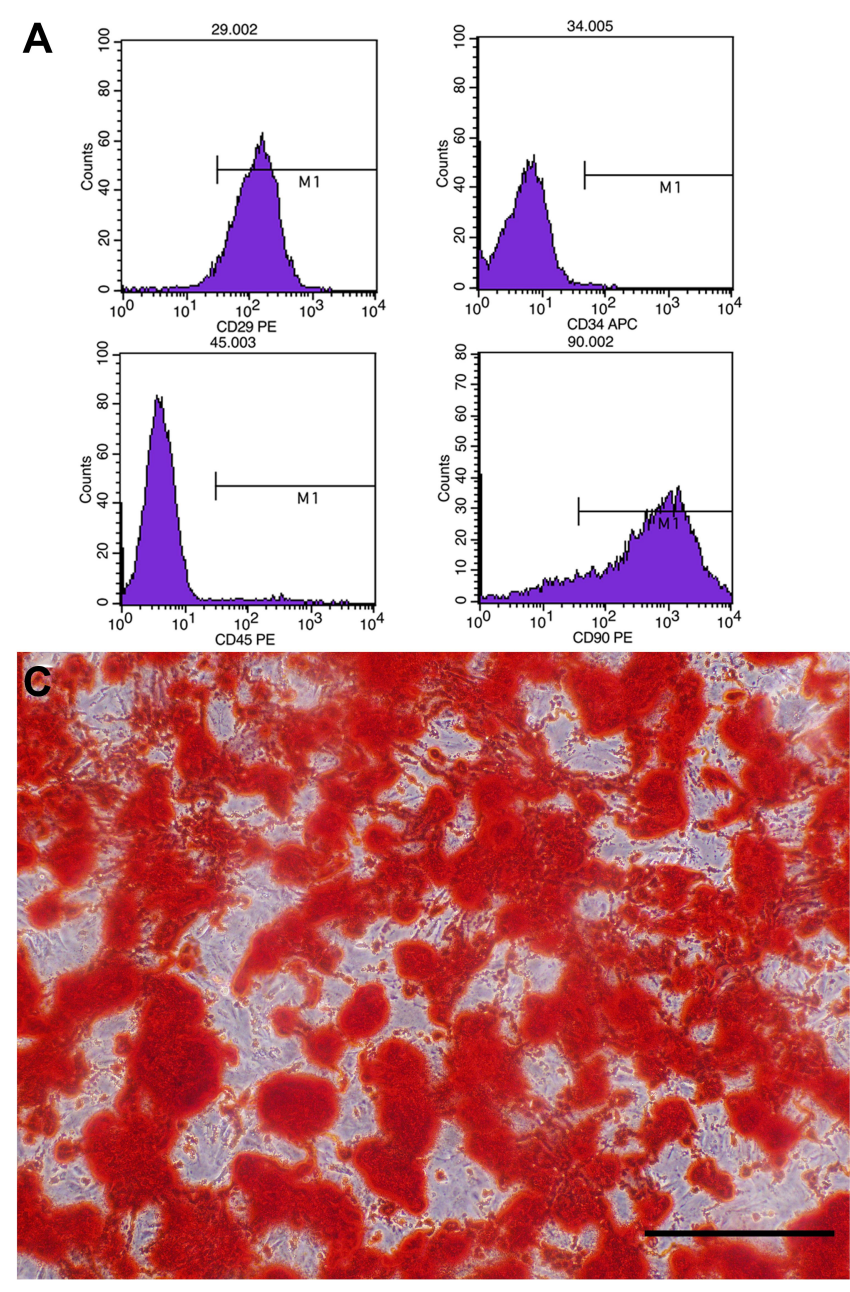

Figure 3 Expression of ASC surface marks detected by flow cytometry (A). Three lineages differentiation and corresponding identification of ADSCs (B-D). (B) alcian blue staining for chondrogenic induction. (C) alizarin red staining for osteogenic induction; (D) Oil red $O$ staining for adipogenic induction; Scale bars: $200 \mu \mathrm{m}$ in $\mathrm{C}$ and $\mathrm{D}, 500 \mu \mathrm{m}$ in (B).

(Figure 4C). The initial number of ASCs seeded within a single GM was controllable by regulating the initial cell suspension density. The initial cell seeding density of $2 \times 10^{6} / \mathrm{mL}$ enabled rapid proliferation, resulting in sufficient cells per GM at 4 days, which was chosen for subsequent experiments (Figure 4D).

LSCM images showed that at $6 \mathrm{~h}$, a large number of ASCs were tightly attached to GMs. At 2 days, ASCs grew well and appeared to be uniformly distributed with almost no dead cells. With the extension of culture time, the number of ASCs increased significantly at 4 days. Interestingly, multiple GMs were also observed to assemble together (Figure $4 \mathrm{~A}$ ).

SEM (Figure 4B) results showed that ASCs were attached to the surface of GMs after inoculation on GMs for $6 \mathrm{~h}$. After 2 days, ASCs in GMs showed good morphology and uniform density. At 4 days, ASCs secreted

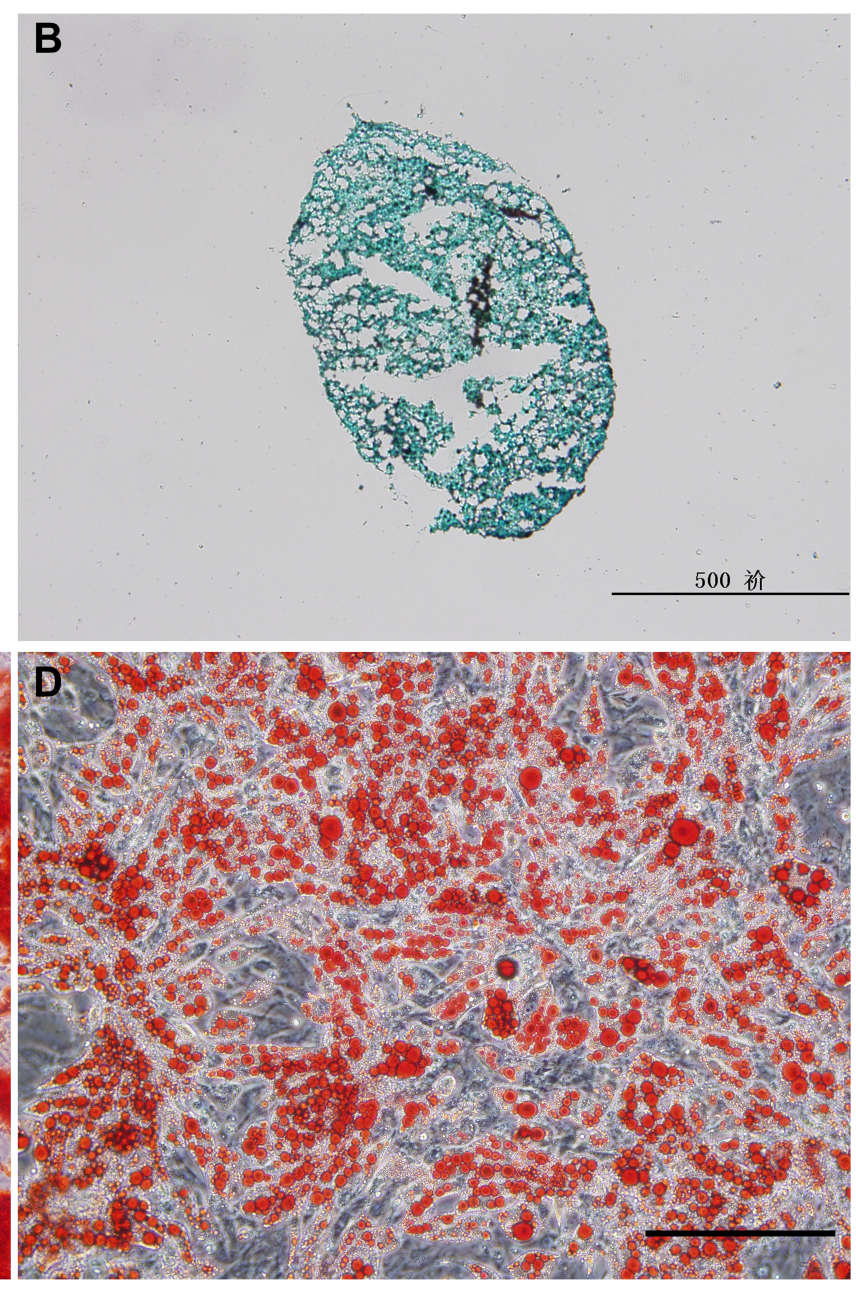

a large amount of ECMs completely encapsulating multiple GMs to form tissue-like microunits.

ASCs showed a strong proliferation ability and adhesion ability on the surface of GMs. Therefore, we concluded that ASCs have good biocompatibility with GMs. Porous GMs can be used as an injectable carrier for ASCs in tendon tissue engineering.

\section{Results of the AFI and 3D Intensity Footprints}

At 1 day, all groups had very low AFI scores (ASCs + GMs group: $-122.97 \pm 10.65$, ASCs group: $-120.06 \pm 5.59$, GMs group: $-126.07 \pm 7.57$, Defect group: $-117.90 \pm 17.12$ ). Subsequently, the general tendency of all groups increased consecutively. On day 14, the ASCs+GMs (-38.49 \pm 2.94$)$ group was the first to exceed the $50 \%$ functional recovery line and had a significantly higher AFI than the GMs 
A
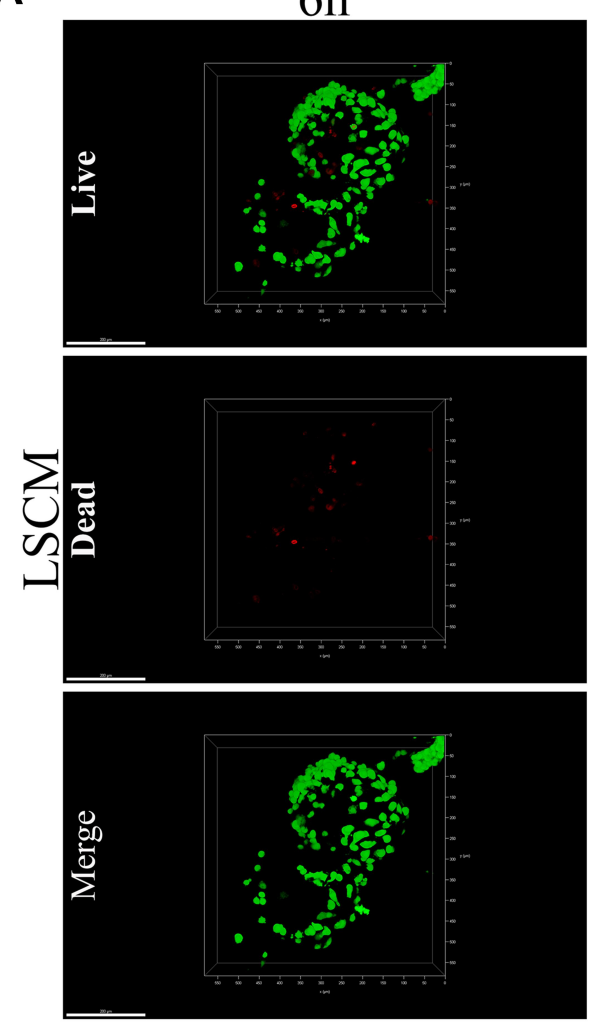

B

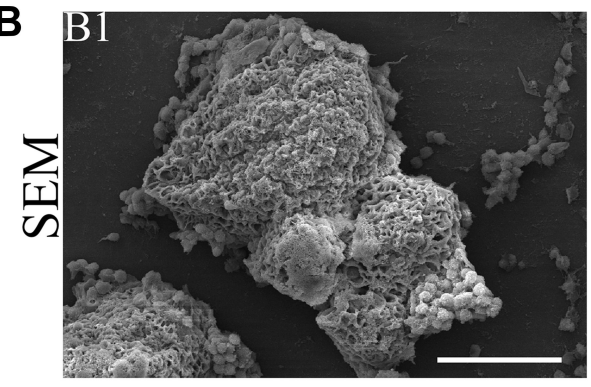

C

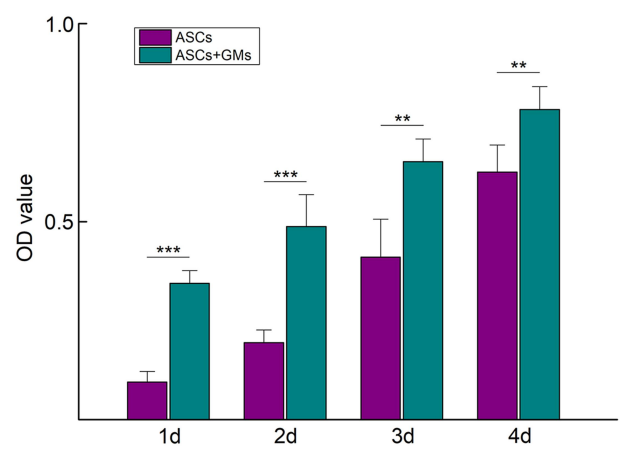

$2 d$
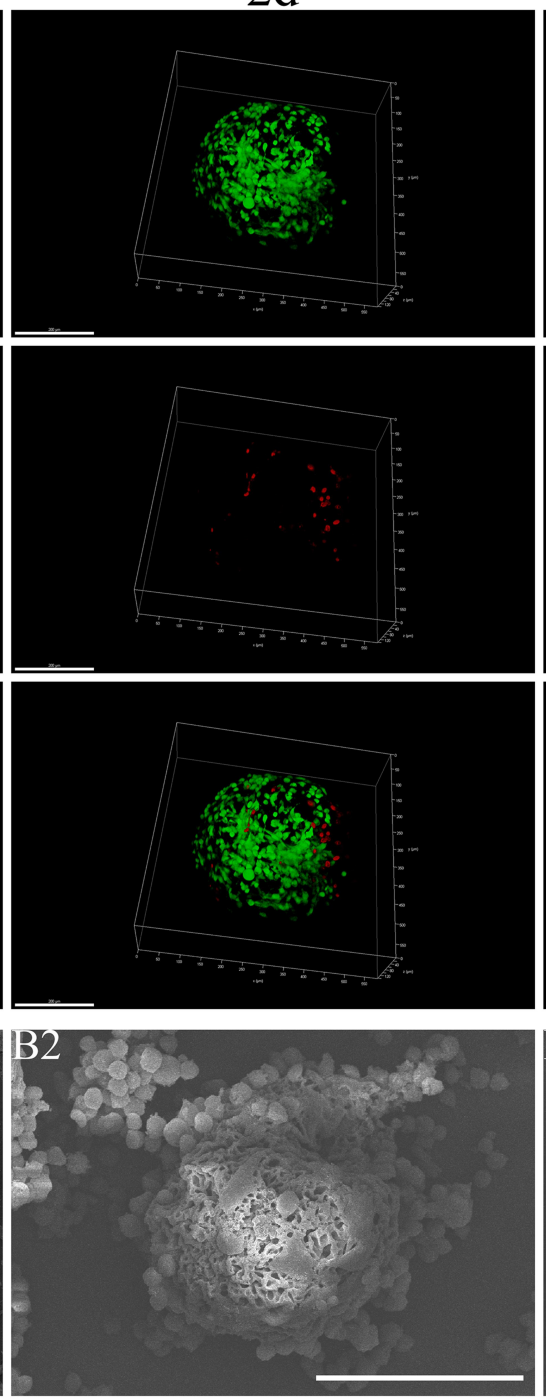

D
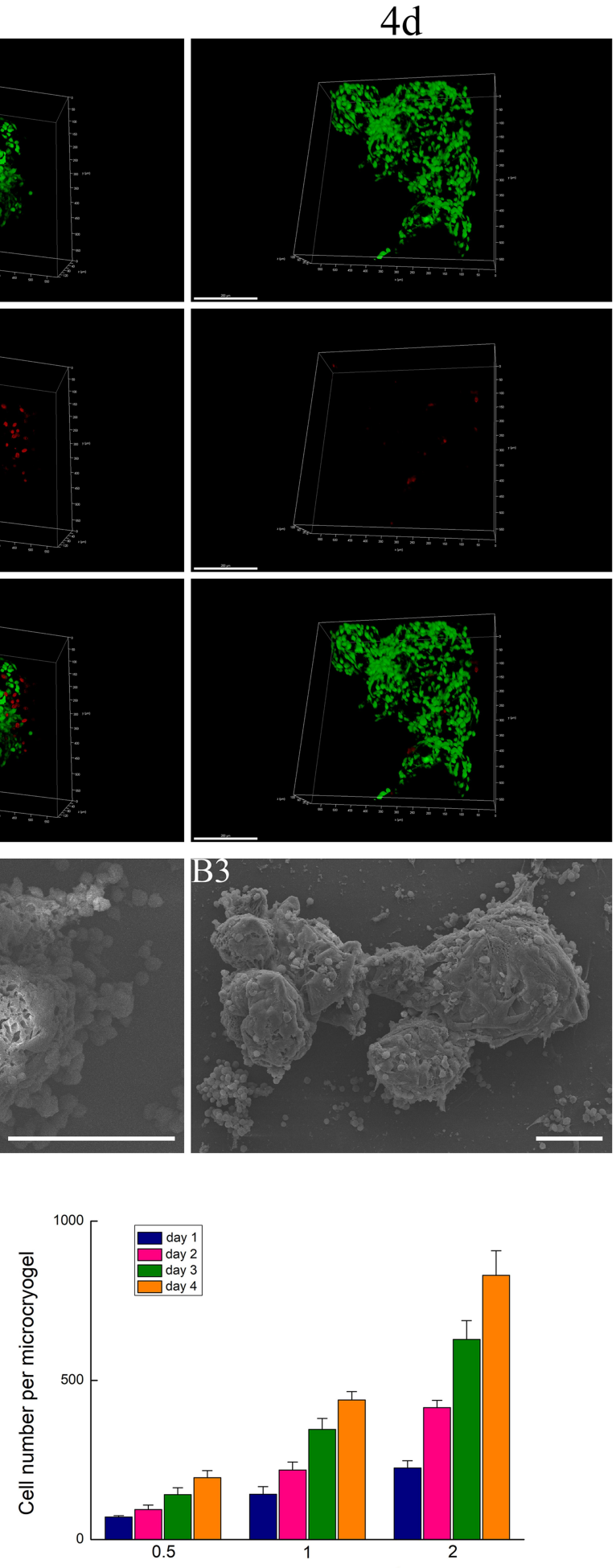

Cell Seeding Desity $\left(\times 10^{6} / \mathrm{ml}\right)$

Figure 4 Laser scanning confocal microscope (LSCM) images of ASCs seeded in GMs showed attachment at $6 \mathrm{~h}$ postseeding, proliferation at 2 days and microunits aggregated after 4 days of culture (A). Green fluorescence represents viable cells. Red fluorescence represents dead cells. Scanning electron microscopy (SEM) of GMs laden with ASCs at $6 \mathrm{~h}$ and 2 days (B I, B2) postseeding and microunits aggregated and packaged with a large amount of secreted ECM after 4 days of culture (B3). Comparison of single ASC cultures with ASC-laden GM cocultures (C). Quantification of ASC loading and proliferation in GMs with different initial loading densities (D). Scale bars: $200 \mu \mathrm{m}$ in $A$ and $100 \mu \mathrm{m}$ in $\mathrm{B}$. Data are presented as the mean $\pm \mathrm{SD}$; statistical analyses were performed with the unpaired Student's $t$-test; $* * \mathrm{P}<0.0 \mathrm{I}$; ***P<0.00I. 


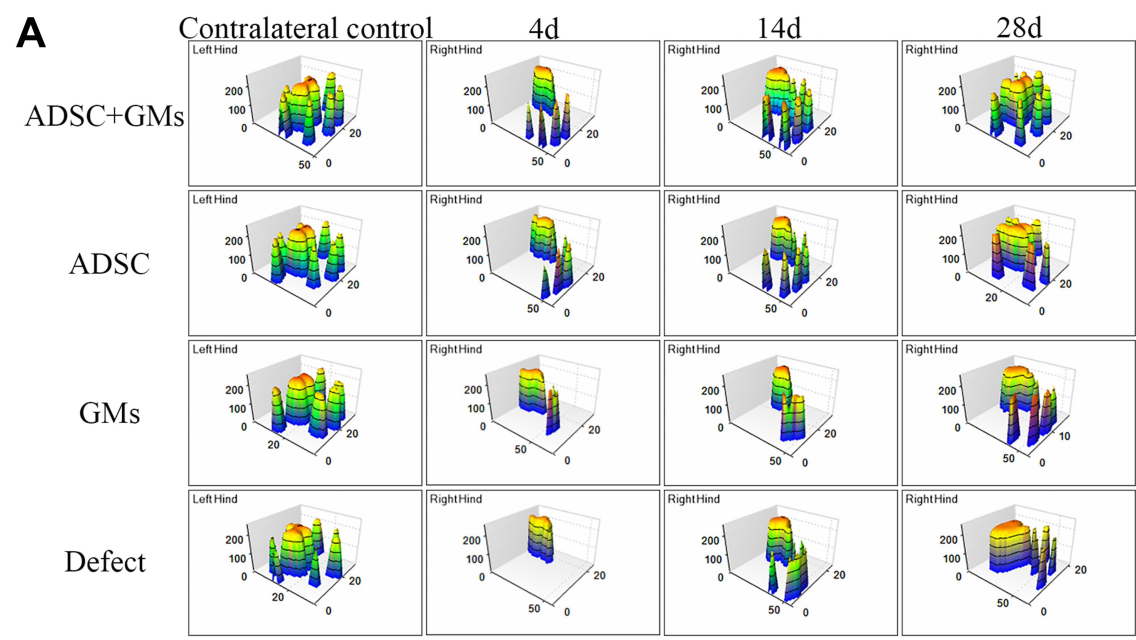

B
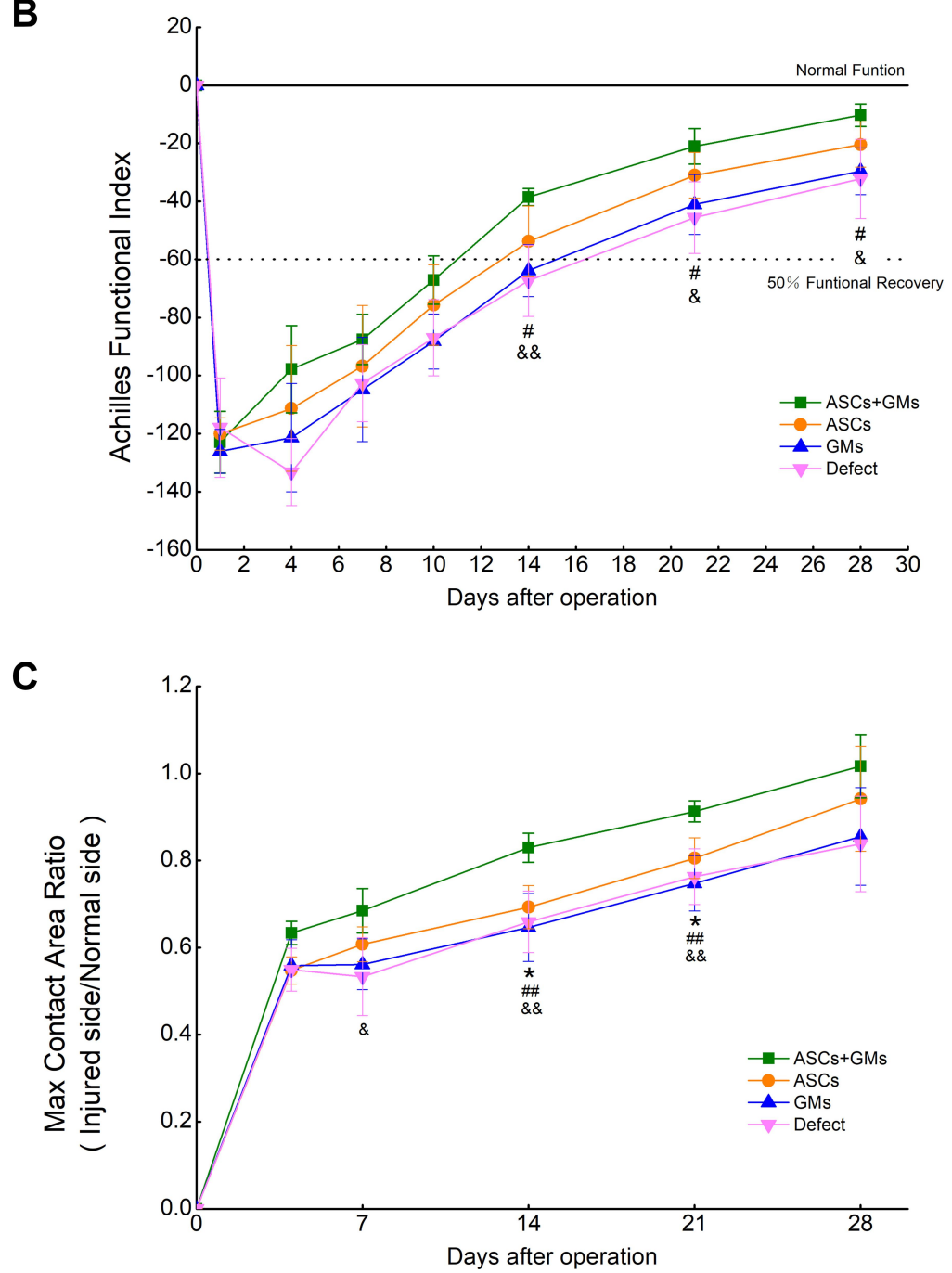

Figure $53 \mathrm{D}$ foot print strength observation of the four groups at 4, 14 and 28 days after surgery (A); The mean AFI values with standard deviation error bars for each group $(n=4)$ versus time $(\mathbf{B})$. The mean Max contact area ratio (injured side/normal side) values with standard deviation error bars for each group versus time $(\mathbf{C})$. $* P<0.05$ vs the ASCs group; \#P<0.05 vs the GMs group \#\#P0.01 vs the GMs group; \&P<0.05 vs the Defect group; \&\&P<0.01 vs the Defect group. 
group $(-63.77 \pm 8.96, \mathrm{P}<0.05)$ and the Defect group $(-67.28 \pm 12.29, \mathrm{P}<0.01)$. All groups displayed a slow improvement from day 14 to day 28. By 28 days, the ASCs + GMs group had improved further $(-10.31 \pm 3.89)$, followed by the ASCs group ( $-20.39 \pm 7.77)$, GMs group $(-29.58 \pm 8.02)$ and finally the Defect group $(-32.21$ \pm 13.65 ) (Figure 5B). Incidentally, the $3 \mathrm{D}$ foot print strength showed that all groups gradually recovered postoperative foot print strength, but both the speed and the degree of recovery in the ASCs+GMs group were better than those in the other three groups (Figure 5A).

The max contact area (injured side/normal side) ratio also reflected the recovery of motor function. Obvious improvements in the ratio were found beginning at 14 day after transplantation in the ASCs+GMs groups $(82.95 \pm 3.35 \%)$, but no such improvement was observed in the other three group. At 21 day, the ratio in the ASCs + GMs group $(91.28 \pm 2.44 \%)$ was significantly superior to those in the ASCs group $(80.53 \pm 4.68 \%, \mathrm{P}<0.05)$, the GMs group $(76.3 \pm 6.4 \%, \mathrm{P}<0.01)$, and the Defect group $(74.77 \pm 6.33 \%, \mathrm{P}<0.01)$, and there were no significant differences between the four groups at 28 days (Figure 5C).

\section{Macroscopic Assessment}

Two weeks after surgery, small defects were clearly observed in the Defect group and the GMs group, whereas in the ASCs+GMs group and the ASCs group, the defect was almost invisible. The GMs and Defect groups had fewer repair tissues and were darker in color than the other two groups (Figure 6A1-A4). At 4 weeks postoperatively, no obvious defect was found in either group. In the Defect group and GMs group, the newborn callus was slightly darker than the surrounding tissue. In contrast, the callus in the other two groups was almost white. The general morphology of the ASCs+GMs group was also closer to normal (Figure 6B1-B4). At 2 weeks after surgery, the gross rating scores of each group were significantly lower than those of the normal Achilles tendon (Normal: 17.0, $\mathrm{P}<0.001$ ), and the scores of the ASCs + GMs group $(8.7 \pm 1.5)$ were higher than those of the ASCs group (7.0 \pm 1.7$)(\mathrm{P}>0.05)$ and the GMs group (5.3 \pm 1.5$)$ $(\mathrm{P}>0.05)$ and were significantly higher than those of the Defect group $(4.7 \pm 1.2)(\mathrm{P}<0.05)$. At $4 \mathrm{w}$ postoperatively, the ASCs+GMs group (12.3 \pm 2.8$)$ had the highest scores, but these were scores significantly lower than those of the normal Achilles tendon group ( $\mathrm{P}<0.05)$; furthermore, the ASCs group (9.5 \pm 2.5$)$ and GMs group (9.5 \pm 3.0 ) had a significantly lower score than the normal Achilles tendon group $(\mathrm{P}<0.01)$, and the Defect group $(8.5 \pm 2.1)$ had a significantly lower score than the normal Achilles tendon group $(\mathrm{P}<0.001)$ (Figure 7A).

It is worth mentioning that the length of the ASCs +GMs group remained almost unchanged, namely, from $12.21 \pm 0.64 \mathrm{~mm}$ to $12.52 \pm 0.82 \mathrm{~mm}$. This length was the shortest among the four groups [2 weeks: (ASCs group: $13.48 \pm 0.49 \mathrm{~mm}$ ), (GMs group: $15.32 \pm 1.17 \mathrm{~mm}, \mathrm{P}<$ 0.001), (Defect group: $14.43 \pm 0.8 \mathrm{~mm}, \mathrm{P}<0.01$ ); 4 weeks: (ASCs group: $14.49 \pm 1.09 \mathrm{~mm}, \mathrm{P}<0.05$ ), (GMs group: $15.24 \pm 1.3 \mathrm{~mm}, \mathrm{P}<0.01$ ), (Defect group: 15.56 $\pm 0.93 \mathrm{~mm}, \mathrm{P}<0.01)]$ but significantly longer than that of the normal tendon $(10.48 \pm 0.35 \mathrm{~mm})$. However, the other three groups showed a slight increase and significantly longer length than the normal tendon group $(\mathrm{P}<$ 0.001) (Figure 7B).

Starting with a cross-sectional area of $12.12 \pm 0.44 \mathrm{~mm}^{2}$ at 2 weeks, the ASCs+GMs group showed a decrease to $11.03 \pm 1.03 \mathrm{~mm}^{2}$ at 4 weeks. The value in this group was significantly higher than that of the GMs group (9.69 $\left.\pm 0.77 \mathrm{~mm}^{2}, \mathrm{P}<0.05\right)$ and the Defect group (9.09 $\left.\pm 2.03 \mathrm{~mm}^{2}, \mathrm{P}<0.01\right)$ but lower than that of the ASCs group $\left(14.15 \pm 0.79 \mathrm{~mm}^{2}\right)$ at 2 weeks. In contrast, the other three groups (ASCs group: $15.39 \pm 0.88 \mathrm{~mm}^{2}$, GMs group: $13.02 \pm 0.96 \mathrm{~mm}^{2}$, Defect group: $12.39 \pm 1.97 \mathrm{~mm}^{2}$ ) exhibited a rising tendency that was even higher than the experimental group at 4 weeks. All four groups had significantly higher values than the normal tendon group $\left(3.01 \pm 0.29 \mathrm{~mm}^{2}, \quad \mathrm{P}<0.001\right)$ at two time points (Figure 7C).

\section{Biomechanical Analysis}

The ultimate failure load steadily increased from 52.92 $\pm 9.06 \mathrm{~N}$ to $65.08 \pm 4.50 \mathrm{~N}$ in the ASCs+GMs group after 2 and 4 weeks. Compared with the GMs group ( 2 weeks: $38.22 \pm 6.04 \mathrm{~N}, \mathrm{P}<0.05$; 4 weeks: $55.26 \pm 5.37 \mathrm{~N}, \mathrm{P}<0.05$ ) and the Defect group (2 weeks: $34.58 \pm 4.87 \mathrm{~N}, \mathrm{P}<0.01$; 4 weeks: $54.02 \pm 7.19 \mathrm{~N}, \mathrm{P}<0.05$ ), the ultimate failure load was significantly greater at the two time points. The ASCs group increased rapidly from $46.28 \pm 9.93 \mathrm{~N}$ to $66.86 \pm 3.17$ $\mathrm{N}$ and was significantly stronger than the normal tendon group, the GMs group and the Defect group at 4 weeks. However, the ASCs group, the GMs group and the Defect group had significantly lower values than the normal tendon group (58.38 $\pm 3.26 \mathrm{~N}$ ) at 2 weeks (Figure 7D).

At 2 weeks, the stiffness of the ASCs+GMs group, the ASCs group, the GMs group and the Defect group were 

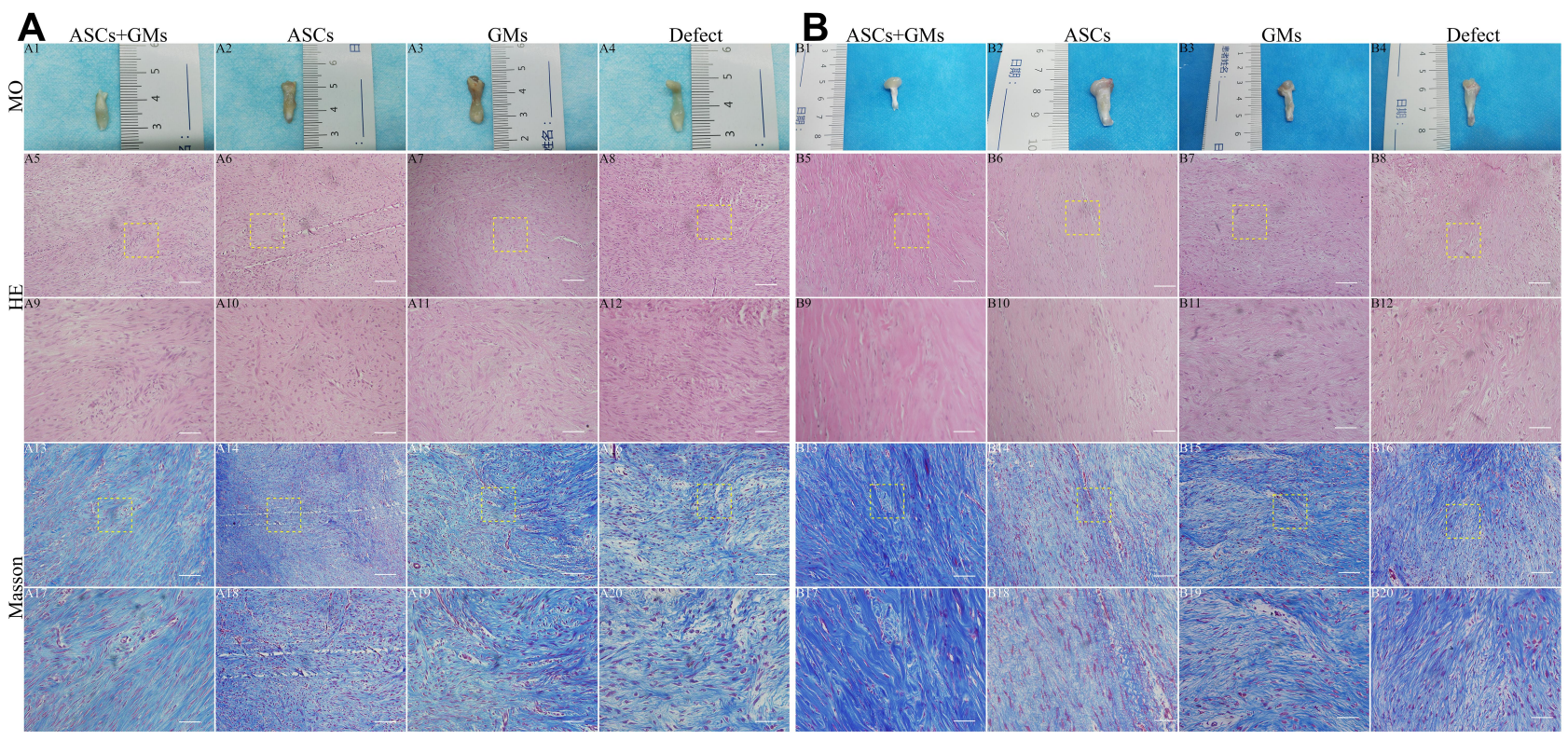

Figure 6 Macroscopic observation (MO) and histological evaluation of repaired tissue at 2 and 4 weeks after surgery. Gross appearance of the repaired tendon defects in the four groups (AI-A4, B I-B4). Hematoxylin \& eosin (HE) staining (A5-AI2, B5-BI2) and Masson staining (AI3-A20, B I3-B20) of repaired tissue. The yellow rectangle indicates the area shown in the below images at higher magnification. Scale bars: $100 \mu \mathrm{m}$ in (A5-A20, B5-B20).

A

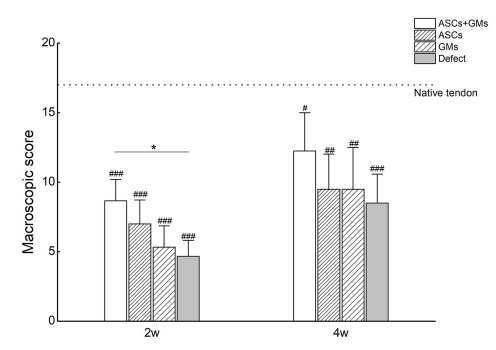

D

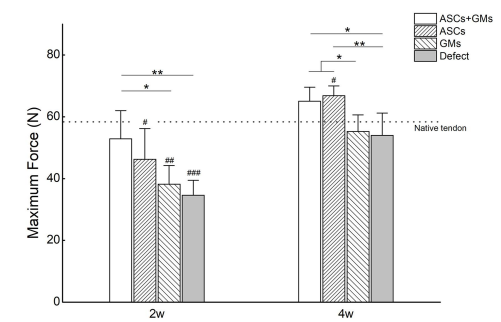

B

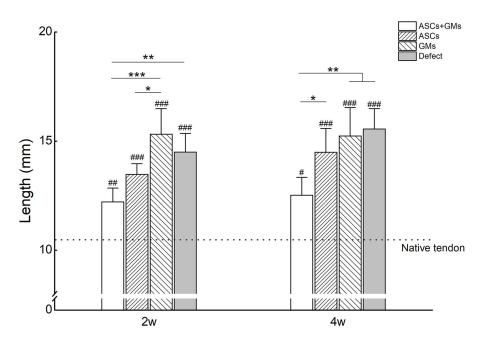

$\mathbf{E}$

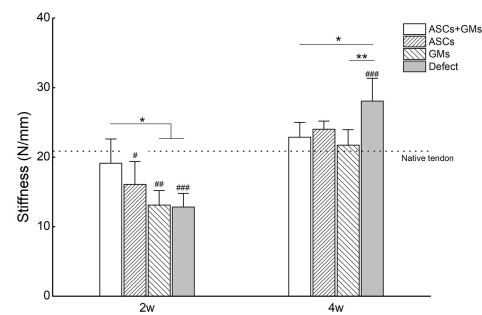

C

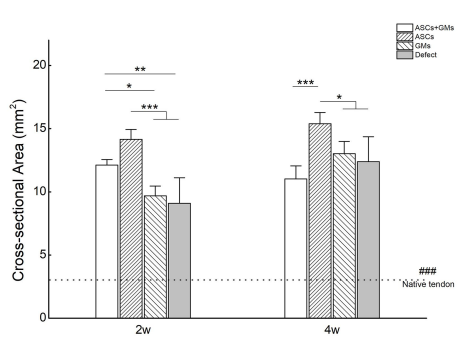

$\mathbf{F}$

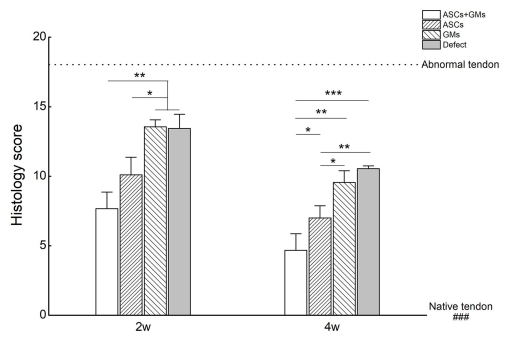

Figure 7 Results of the macroscopic scoring of repaired tissue $(\mathbf{A})$, the length of repaired tissue $(\mathbf{B})$, the cross-sectional area of repaired tissue (C), the maximum force of repaired tissue $(\mathbf{D})$, the stiffness of repaired tissue $(\mathbf{E})$, and the histology score of repaired tissue $(\mathbf{F})$. Data are presented as the mean $\pm S D ; * P<0.05 ; * * P<0.01$; $* * * P<0.00 I$; $\# \mathrm{P}<0.05$ vs the normal tendon; \#P $<0.01$ vs the normal tendon; \#\#P $<0.00$ I vs the normal tendon.

$19.14 \pm 3.47 \mathrm{~N} / \mathrm{mm}, 16.08 \pm 3.31 \mathrm{~N} / \mathrm{mm}, 13.1 \pm 2.08 \mathrm{~N} / \mathrm{mm}$ and $12.84 \pm 1.95 \mathrm{~N} / \mathrm{mm}$, respectively. Among these groups, the ASCs+GMs group had slightly smaller values than the normal tendon group $(20.88 \pm 1.93 \mathrm{~N} / \mathrm{mm})$. The other three groups had significantly lower values than the normal tendon group. In contrast, at 4 weeks postoperatively, all four groups $(22.88 \pm 2.13 \mathrm{~N} / \mathrm{mm}, 24.02 \pm 1.17 \mathrm{~N} / \mathrm{mm}, 21.74$ $\pm 2.22 \mathrm{~N} / \mathrm{mm}$ and $28.08 \pm 3.26 \mathrm{~N} / \mathrm{mm}$ ) had higher values than the normal tendon group, but only the Defect group $(\mathrm{P}<0.001)$ had a statistical significance (Figure 7E).

\section{Histological Analysis}

H\&E staining showed that at 2 weeks, the ends of the severed edges were visible in each group, and a small 
amount of longitudinal fibrous tissue was found in the ASCs+GMs group and ASCs group (Figure 6A5-A12). At 4 weeks, the edges were relatively invisible in each group. The ASCs+GMs group and the ASCs group had more oriented fibers and a higher density of spindle cells. Cellularity in the ASCs+GMs group was the lowest, although all groups had higher cell numbers than the native tendon (Figure 6B5-B12).

Masson staining revealed at 2 weeks postoperative, a few fine blue-stained collagen fibers were observed in the ASCs+GMs group and the ASCs group, among which the ASCs+GMs group was better, whereas the GMs group and the Defect group had a clear blue matrix (Figure 6A13-A20). At 4 weeks, the blue collagen fibers of the ASCs + GMs group were more aligned, thicker and longer than those of the other three groups (Figure 6B13-B20).

The results of Sirius red staining by polarized light were observed at 2 weeks, and the ASCs+GMs group showed yellow and green refractive hybrids, indicating that it contained collagen I and collagen III. The ASCs group had more green refraction, giving priority to collagen III. The refraction of the other two groups was greenish, and some fibers displayed obvious fragmentation. At 4 weeks after surgery, with the extension of time, the ASCs+GMs group and the ASCs group presented a stronger orange or bright-red refractive light, and the collagen alignment was more oriented. However, the ASCs group still had a few green refractive lights. The refraction of the GMs group and the Defect group was also yellowish green, and the fiber orientation was also disordered (Figure 8).

Immunohistochemical findings showed that collagen I staining was more deeply stained in the ASCs+GMs group and the ASCs group was deeper than the other two groups at two time points. Staining for collagen III showed relatively localized and sporadic staining in the ASCs+GMs group and the ASCs group at 2 and 4 weeks compared to the evenly distributed staining in the remaining two groups (Figure 9).

These observations were consistent with the results of the histology score (Figure 7F). The total histology score of abnormal tendons was 18 , while that of native tendons was 0 . At 2 weeks, the scores of the ASCs+GMs group, the ASCs group, the GMs group and the Defect group were $7.7 \pm 1.2,10.1 \pm 1.3,13.6 \pm 0.5$ and $13.4 \pm 1.0$, respectively. The scores in the ASCs+GMs group $(\mathrm{P}<0.01)$ and the ASCs group $(\mathrm{P}<0.05)$ were significantly lower than those in the GMs group and the Defect group. At 4 weeks, the ASCs+GMs group score $(4.7 \pm 1.2)$ was also lower than those of the ASCs group ( $7 \pm 0.9, \mathrm{P}<0.05)$, the GMs group $(9.6 \pm 0.8, \quad \mathrm{P}<0.01)$ and the Defect group $(10.6 \pm 0.2$, $\mathrm{P}<0.001)$.

\section{Discussion}

Management of acute Achilles tendon ruptures has witnessed a drift from an era focused primarily on feasibility strategies to an era focused on treatment optimization, which pays more attention to reducing the incidence of complications and to functional rehabilitation. ${ }^{28,29}$ This progress has been achieved following a transformation from recognized primary surgery to minimally invasive repairs and functional treatments that are in vogue. ${ }^{11,30}$ In addition, current evidence indicates that adjunct biologics such as fibrin glues (adhering rupture ends), ${ }^{31}$ platelet-rich fibrin matrix (releasing highly complex pools of signaling factors), ${ }^{32}$ bone marrow aspirate concentrate (injecting mesenchymal stem cells) ${ }^{33}$ and platelet-rich plasma (releasing more than 300 bioactive proteins), ${ }^{34}$ have the potential to help accelerate tendon healing. There were several reasons for addressing the trend toward minimally invasive injection combined with bioactive agents. Thus, in the present study, we confirmed that primed injectable micro-carrier GMs enable ASC therapy to accelerate the process of tendon regeneration. Consequently, this investigation offers a solid foundation for the clinical application of injectable stem cell carriers.

The core concept of biological scaffolds is to provide a suitable growing microenvironment for seed cells to promote cell proliferation and ECM deposition. Similar to that reported in a previous paper, ${ }^{25}$ the large-aperture structure of porous GMs in this experiment characterized by good biocompatibility not only facilitates the exchange of nutrients and cell metabolism products but also provides an appropriate growth microenvironment for cell adhesion and proliferation. Furthermore, porous GMs provide more space for cells to grow into the microsphere to avoid damage by external stress. Laser confocal microscopy showed that ASCs distributed evenly and proliferated rapidly in the GMs at day 2, indicating that the porous GMs had good biocompatibility. Additionally, GMs aggregated together at day 4. Meanwhile, CCK8 quantitative experiments also verified that the GMs had no obvious toxicity to ASCs and promoted the growth rate of cells. Previous papers have shown that the accumulation of ECMs derived from mesenchymal stem cells (MSCs) can enhance the therapeutic effect, which dramatically 


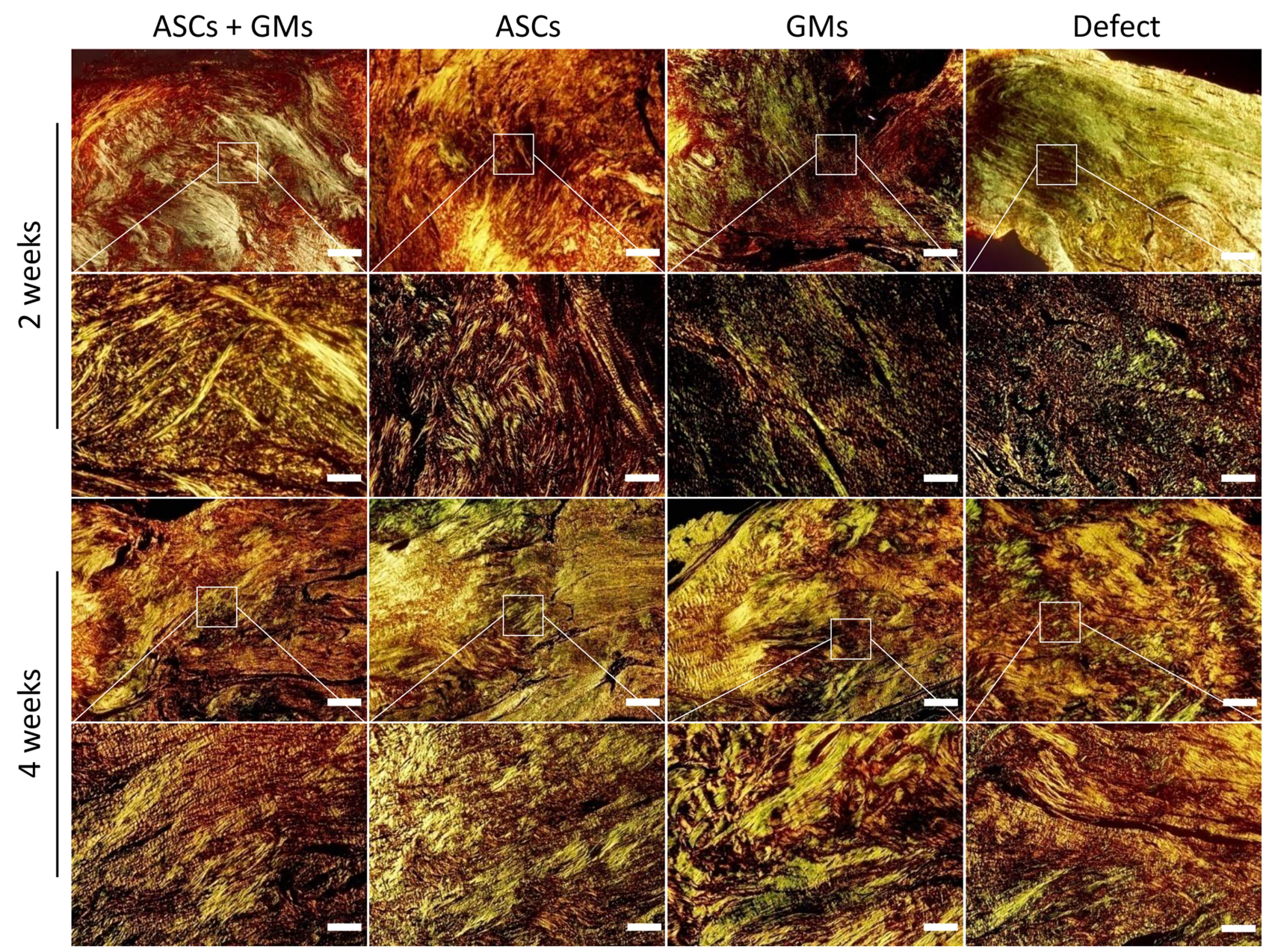

Figure 8 Sirius red staining of repaired tissue at the two time points. The white rectangle indicates the area shown in the below images at higher magnification. Scale bars: $100 \mu \mathrm{m}$.

accelerates MSC proliferation, attachment, spread, migration, secretion and multilineage differentiation potential with a low probability of inducing negative immune responses through activating signaling pathways via biophysical and biochemical cues. ${ }^{35-37}$ In short, ECMs play important roles in maximizing the cell function through appropriate cell-cell and cell-matrix interactions. SEM in this study showed that after the ASCs were cultured on porous GMs for 4 days, there were large numbers of secreted ECM-coated microspheres, and sometimes multiple microspheres could be bundled into tissue-like compounds that we believed could better increase the therapeutic efficacy of ASCs. Moreover, due to the ECM, ASCs loaded onto GMs had a predisposition toward recognition and could be shielded from mechanical insults during injection.

Tissue engineering has been used to directly inject cell suspensions into a lesion site, resulting in cell necrosis and
ECM loss. ${ }^{21,22,38}$ However, it is not advisable to use excessive doses of MSCs to improve the number of surviving cells at the damaged site because of the increased cultivation cost and potential safety hazard. ${ }^{39,40}$ This experiment using porous GM-based injectable cellular carriers seeded within ASCs to constitute biomimetic microunits with larger amount of accumulated ECM could not only realize a high relative density of cells at the lesion but also establish stronger cell-cell and cellECM interactions, avoiding the leakage of dispersed cells into surrounding tissues and reported possible risks such as embolism. ${ }^{41}$ In addition, for further clinical applications, injectable carriers are desirable to regenerate defects of irregular geometries. ${ }^{42}$

The process of tendon healing occurs in three distinct phases: inflammation, proliferation or repair, and remodeling. ${ }^{43}$ It is well known that scar tissue, which is mainly composed of collagen III, is first formed and then is 


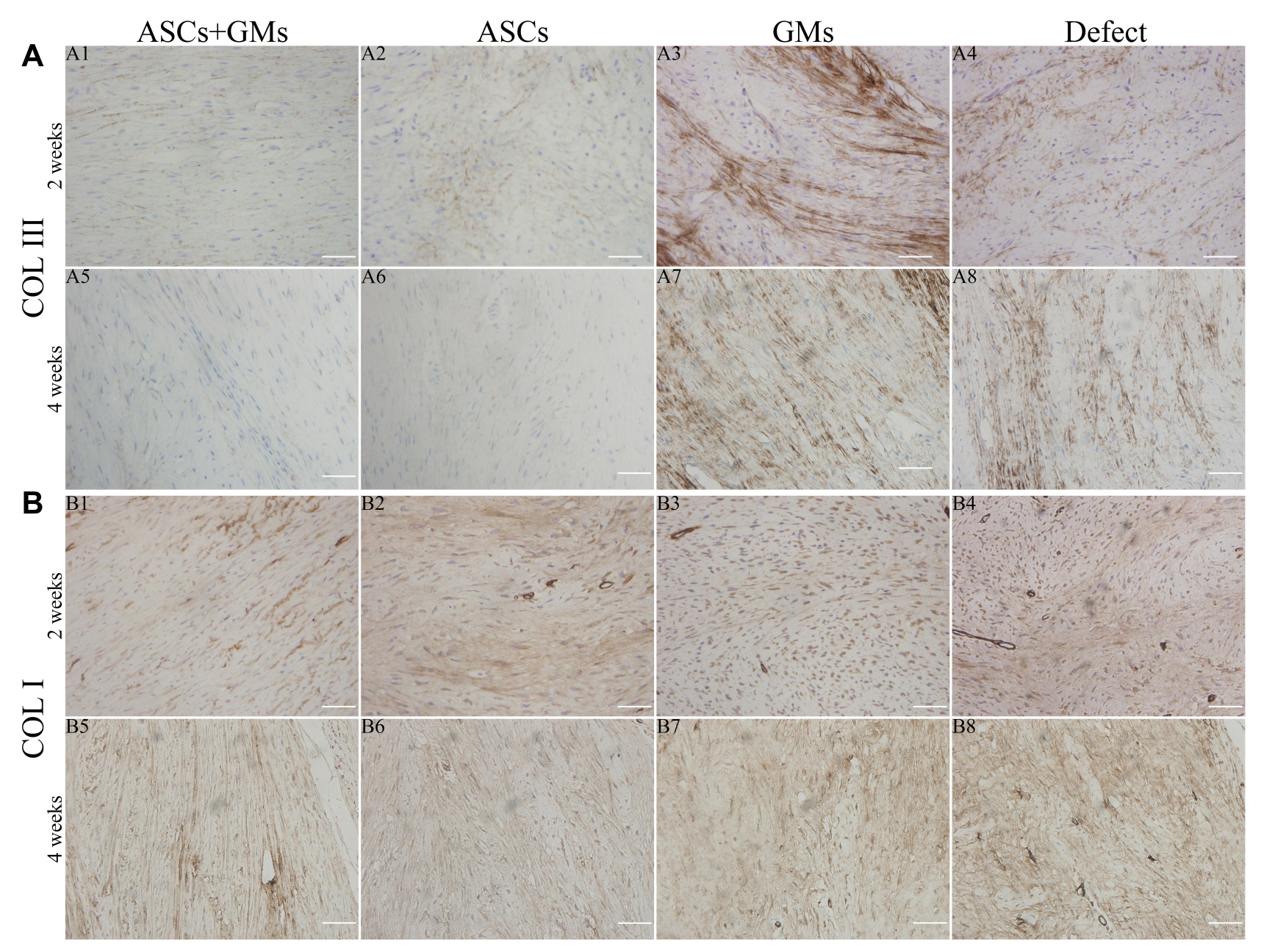

Figure 9 Immunohistochemical staining of repaired tissue for type III collagen (A) and type I collagen (B) at 2 weeks and 4 weeks. Scale bars: $100 \mu$ m.

replaced by collagen I due to continuous reconstruction from mechanical stimulation, which accounts for approximately $95 \%$ of the total collagen in the normal tendon $\mathrm{ECM}^{43}$ All tendon tissue engineering and regenerative medicine is focused on how to optimize this healing process toward mechanical properties as close as possible to those of normal tendon tissue. During this process, the length, cross-sectional area, and ultimate failure load of the Achilles tendon all changed as the biomechanics changed. The biomechanics of the Achilles tendon are closely related to its function. The newborn Achilles tendon constituted by collagen III is usually weak in compensated mechanics, leading to a larger cross-sectional area. When it is then stretched by a force, it easily forms an elongated tendon, thus damaging the function of the Achilles tendon. ${ }^{44}$ In this work, the tendon length in the ASCs+GMs group was significantly shorter than that of the other three groups at 2 and 4 weeks, indicating that the newborn callus in the ASCs+GMs group had a greater resistance to traction. This fact that the control tendons appeared elongated and more slender over time was consistent with the findings by Konerding et al. ${ }^{45}$ The cross-sectional area in the ASCs +GMs group remained larger at 2 weeks but smaller at 4 weeks, whereas the cross-sectional area of the other three groups increased progressively as time elapsed. These results could be explained by the fact that tendon regeneration of the ASCs+GMs group had a faster repair speed, which meant that the ASCs + GMs group had more collagen fiber bundles, resulting in a relatively larger crosssectional area at 2 weeks, but had a more mature structure and composition of collagen fibers than the other groups, leading to a stronger resistance that resulted in a relatively smaller cross-sectional area at 4 weeks. In agreement with these cross-sectional area data, the ASCs+GMs group showed a higher ultimate failure load at every time point. Furthermore, compared with the normal tendon group, the ASCs + GMs group had already reached the desired high tear resistance at 2 weeks. The other three groups were 
still significantly weaker than both the normal tendon and the experimental groups until 4 weeks. The stiffness in the ASCs+GMs group at the early stage was greater than that of the other three groups, indicating that this group had a higher force transfer efficiency. Remarkably and desirably, the tendon stiffness of the ASCs+GMs group appeared not to be significantly different from that of the normal tendon. However, at 4 weeks postoperatively, the higher stiffness in the defect may cause rerupture resulting from decreasing elasticity and greater stiffness. In summary, the hypothesis that these microunits resulted in superior biomechanics can be affirmed. Furthermore, the histopathological staining results also provided strong support for the abovementioned mechanical results and therefore was as reliable as the AFI, which directly evaluated the actual Achilles functional recovery condition after repair in the rat model. ${ }^{46}$ In the experiment, AFI values of the ASCs+GMs group were larger than those of the other three groups in each tested period. Furthermore, the ASCs+GMs group was the first group to reach the $50 \%$ functional line, implying a decrease in time required for functionality to return to the tendon. Meanwhile, the 3D foot-printing intensity and max contact area (injured side/normal side) also indicated that the ASCs+GMs group recovered the function of plantar flexion relatively quickly.

The limitation of this study was that the model of clean transection of the midsubstance of the Achilles tendon was not a direct mimic because avulsion rupture in the clinic exhibits mop-like ends interposed with tissue fragments. However, the operability of creating such ragged ends was not easy to pursue because the resulting lesions were less likely to be reproducible. Another consideration was the specific mechanism of how the compounds of GMs seeded with ASCs influence tendon regeneration and repair in vivo. Consequently, our group will explore the possible ultimate cell fate by tracking the cell location, migration and differentiation at the rupture site. Furthermore, more research is required for the clinical application of this injectable biomaterial in human subjects.

\section{Conclusions}

In sum, we have successfully validated the biocompatibility and characterization of injectable cellular microcarriers composed of ASCs for cell delivery through a series of experiments. Porous GMs can allow cells to facilitate cell proliferation with extensive ECM deposition and to survive injection. This novel minimally invasive injection therapy was indeed effective in accelerating Achilles tendon healing following rupture.

\section{Informed Consent}

Informed consent was obtained from all individual participants included in the study.

\section{Acknowledgments}

We are very grateful to Academician Lu Shibi of the Chinese Academy of Engineering for his valuable experience and guidance in the experiment. As students, we will be always in memory of you. I would also like to thank my family, especially my father Yang Xiping and my love Li Yuan, for their support and care during this period.

\section{Funding}

This study was supported by the Beijing Key Laboratory Innovation and development project (Z1611000050 16059), Key projects of Military Medical Innovation Engineering (16CXZ044), The military's 13th five-year priorities (BWS13C029), National Natural Science Foundation of China (31640029).

\section{Disclosure}

The authors declare that they have no conflicts of interest for this work.

\section{References}

1. Ganestam A, Kallemose T, Troelsen A, Barfod KW. Increasing incidence of acute Achilles tendon rupture and a noticeable decline in surgical treatment from 1994 to 2013. A nationwide registry study of 33,160 patients. Knee Surg Sports Traumatol Arthrosc. 2016;24 (12):3730-3737.

2. Lantto I, Heikkinen J, Flinkkilä T, et al. Epidemiology of Achilles tendon ruptures: increasing incidence over a 33-year period. Scand J Med Sci Sports. 2015;25(1):e133-e138. doi:10.1111/sms.12253

3. Huttunen TT, Kannus P, Rolf C, et al. Acute Achilles tendon ruptures: incidence of injury and surgery in Sweden between 2001 and 2012. Am J Sports Med. 2014;42(10):2419-2423. doi:10.1177/036354 6514540599

4. Vosseller JT, Ellis SJ, Levine DS, et al. Achilles tendon rupture in women. Foot Ankle Int. 2013;34(1):49-53. doi:10.1177/ 1071100712460223

5. Seeger JD, West WA, Fife D, et al. Achilles tendon rupture and its association with fluoroquinolone antibiotics and other potential risk factors in a managed care population. Pharmacoepidemiol Drug Saf. 2006;15(11):784-792. doi:10.1002/pds.1214

6. Mahieu NN, Witvrouw E, Stevens V, Van Tiggelen D, Roget P. Intrinsic risk factors for the development of Achilles tendon overuse injury: a prospective study. Am J Sports Med. 2006;34(2):226-235.

7. Sorrenti SJ. Achilles tendon rupture: effect of early mobilization in rehabilitation after surgical repair. Foot Ankle Int. 2006;27 (6):407-410. doi:10.1177/107110070602700603 
8. Ma GW, Griffith TG. Percutaneous repair of acute closed ruptured Achilles tendon: a new technique. Clin Orthop Relat Res. 1977; 128:247-255.

9. Assal M, Jung M, Stern R, et al. Limited open repair of Achilles tendon ruptures: a technique with a new instrument and findings of a prospective multicenter study. J Bone Joint Surg Am. 2002;84 (2):161-170. doi:10.2106/00004623-200202000-00001

10. Olsson N, Silbernagel KG, Eriksson BI, et al. Stable surgical repair with accelerated rehabilitation versus nonsurgical treatment for acute Achilles tendon ruptures: a randomized controlled study. Am J Sports Med. 2013;41(12):2867-2876. doi:10.1177/0363546513503282

11. Yang X, Meng H, Quan Q, Peng J, Lu S, Wang A. Management of Acute achilles tendon ruptures: a review. Bone Joint Res. 2018;7(10):561-569.

12. Okamoto N, Kushida T, Oe K, et al. Treating Achilles tendon rupture in rats with bone-marrow-cell transplantation therapy. J Bone Joint Surg Am. 2010;92(17):2776-2784. doi:10.2106/JBJS.I.01325

13. Komatsu I, Wang JH-C, Iwasaki K, et al. The effect of tendon stem/ progenitor cell (TSC) sheet on the early tendon healing in a rat Achilles tendon injury model. Acta Biomater. 2016;42:136-146. doi:10.1016/j.actbio.2016.06.026

14. Juncosa-Melvin N, Boivin GP, Galloway MT, et al. Effects of cell-tocollagen ratio in stem cell-seeded constructs for Achilles tendon repair. Tissue Eng. 2006;12(4):681-689. doi:10.1089/ten.2006.12.681

15. Rickert M. BMP-14 gene therapy increases tendon tensile strength in a rat model of Achilles tendon injury. J Bone Joint Surg Am. 2008;90 (2):445; author reply 445-6.

16. Sivasubramaniyan K, Ilas DC, Harichandan A, et al. Bone marrowharvesting technique influences functional heterogeneity of mesenchymal stem/stromal cells and cartilage regeneration. Am J Sports Med. 2018;46(14):3521-3531. doi:10.1177/0363546518804807

17. Piryaei A, Valojerdi MR, Shahsavani M, Baharvand H. Differentiation of bone marrow-derived mesenchymal stem cells into hepatocyte-like cells on nanofibers and their transplantation into a carbon tetrachloride-induced liver fibrosis model. Stem Cell Rev. 2011;7(1):103-118.

18. DelaRosa O, Lombardo E, Beraza A, et al. Requirement of IFN-gamma-mediated indoleamine 2,3-dioxygenase expression in the modulation of lymphocyte proliferation by human adipose-derived stem cells. Tissue Eng Part A. 2009;15 (10):2795-2806. doi:10.1089/ten.tea.2008.0630

19. Gonzalez MA, Gonzalez-Rey E, Rico L, et al. Treatment of experimental arthritis by inducing immune tolerance with human adipose-derived mesenchymal stem cells. Arthritis Rheum. 2009;60 (4):1006-1019. doi:10.1002/art.24405

20. Gonzalez MA, Gonzalez-Rey E, Rico L, et al. Adipose-derived mesenchymal stem cells alleviate experimental colitis by inhibiting inflammatory and autoimmune responses. Gastroenterology. 2009;136(3):978-989. doi:10.1053/j.gastro.2008.11.041

21. Thai HM, Juneman E, Lancaster $J$, et al. Implantation of a three-dimensional fibroblast matrix improves left ventricular function and blood flow after acute myocardial infarction. Cell Transplant. 2009;18(3):283-296. doi:10.3727/096368909788535004

22. Liu W, Li Y, Zeng Y, et al. Microcryogels as injectable 3-D cellular microniches for site-directed and augmented cell delivery. Acta Biomater. 2014;10(5):1864-1875. doi:10.1016/j.actbio.2013.12.008

23. Drury JL, Mooney DJ. Hydrogels for tissue engineering: scaffold design variables and applications. Biomaterials. 2003;24 (24):4337-4351. doi:10.1016/S0142-9612(03)00340-5

24. Place ES, Evans ND, Stevens MM. Complexity in biomaterials for tissue engineering. Nat Mater. 2009;8(6):457-470.

25. Li Y, Liu W, Liu F, et al. Primed 3D injectable microniches enabling low-dosage cell therapy for critical limb ischemia. Proc Natl Acad Sci US A. 2014;111(37):13511-13516. doi:10.1073/pnas.1411295111

26. Stoll C, John T, Conrad C, et al. Healing parameters in a rabbit partial tendon defect following tenocyte/biomaterial implantation. Biomaterials. 2011;32(21):4806-4815. doi:10.1016/j.biomaterials. 2011.03.026
27. Murrell GAC, Lilly EG, Davies H, et al. The Achilles Functional Index. J Orthop Res. 1992;10(3):398-404. doi:10.1002/ jor. 1100100313

28. Nilsson-Helander K, Thomeé R, Grävare-Silbernagel K, et al. The Achilles tendon Total Rupture Score (ATRS): development and validation. Am J Sports Med. 2007;35(3):421-426. doi:10.1177/ 0363546506294856

29. Twaddle BC, Poon P. Early motion for Achilles tendon ruptures: is surgery important? A randomized, prospective study. Am J Sports Med. 2007;35(12):2033-2038. doi:10.1177/0363546507307503

30. Sheth U, Wasserstein D, Jenkinson R, et al. Practice patterns in the care of Acute achilles tendon ruptures: is there an association with level I evidence? Bone Joint J. 2017;99-b(12):1629-1636. doi:10.1302/0301-620X.99B12.BJJ-2017-0465.R1

31. Knobe M, Gradl G, Klos K, et al. Is percutaneous suturing superior to open fibrin gluing in acute Achilles tendon rupture? Int Orthop. 2015;39(3):535-542. doi:10.1007/s00264-014-2615-4

32. Alviti F, Gurzì M, Santilli V, et al. Achilles tendon open surgical treatment with platelet-rich fibrin matrix augmentation: biomechanical evaluation. J Foot Ankle Surg. 2017;56(3):581-585. doi:10.1053/ j.jfas.2017.01.039

33. Stein BE, Stroh DA, Schon LC. Outcomes of acute Achilles tendon rupture repair with bone marrow aspirate concentrate augmentation. Int Orthop. 2015;39(5):901-905.

34. Zou J, Mo X, Shi Z. A prospective study of platelet-rich plasma as biological augmentation for acute Achilles tendon rupture repair. Biomed Res Int. 2016;2016:9364170.

35. Xiong Y, He J, Zhang W, et al. Retention of the stemness of mouse adipose-derived stem cells by their expansion on human bone marrow stromal cell-derived extracellular matrix. Tissue Eng Part A. 2015;21(11-12):1886-1894. doi:10.1089/ten.tea.2014.0539

36. Kuraitis D, Giordano C, Ruel M, et al. Exploiting extracellular matrix-stem cell interactions: a review of natural materials for therapeutic muscle regeneration. Biomaterials. 2012;33(2):428-443. doi:10.1016/j.biomaterials.2011.09.078

37. Lin H, Yang G, Tan J, et al. Influence of decellularized matrix derived from human mesenchymal stem cells on their proliferation, migration and multi-lineage differentiation potential. Biomaterials. 2012;33 (18):4480-4489. doi:10.1016/j.biomaterials.2012.03.012

38. Hamdi H, Planat-Benard V, Bel A, et al. Epicardial adipose stem cell sheets results in greater post-infarction survival than intramyocardial injections. Cardiovasc Res. 2011;91(3):483-491. doi:10.1093/cvr/ cvr099

39. Vadala G, Sowa G, Hubert M, et al. Mesenchymal stem cells injection in degenerated intervertebral disc: cell leakage may induce osteophyte formation. J Tissue Eng Regen Med. 2012;6(5):348-355. doi:10.1002/term.433

40. Seminatore C, Polentes J, Ellman D, et al. The postischemic environment differentially impacts teratoma or tumor formation after transplantation of human embryonic stem cell-derived neural progenitors. Stroke. 2010;41(1):153-159. doi:10.1161/STROKEAHA.109.563015

41. Zhang L, Li K, Liu X, et al. Repeated systemic administration of human adipose-derived stem cells attenuates overt diabetic nephropathy in rats. Stem Cells Dev. 2013;22(23):3074-3086. doi:10.1089/ scd.2013.0142

42. Liu $X$, Jin $X$, Ma PX. Nanofibrous hollow microspheres self-assembled from star-shaped polymers as injectable cell carriers for knee repair. Nat Mater. 2011;10(5):398-406.

43. Docheva D, Müller SA, Majewski M, et al. Biologics for tendon repair. Adv Drug Deliv Rev. 2015;84:222-239. doi:10.1016/j. addr.2014.11.015

44. Silbernagel KG, Steele R, Manal K. Deficits in heel-rise height and Achilles tendon elongation occur in patients recovering from an Achilles tendon rupture. Am J Sports Med. 2012;40(7):1564-1571. doi:10.1177/0363546512447926 
45. Konerding MA, Arlt F, Wellmann A, Li V, Li W. Impact of combinatory growth factor application on rabbit Achilles tendon injury with operative versus conservative treatment: a pilot study. Int $\mathrm{J} \mathrm{Mol} \mathrm{Med}$. 2010;25(2):217-224.
46. Best TM, Collins A, Lilly EG, et al. Achilles tendon healing: a correlation between functional and mechanical performance in the rat. J Orthop Res. 1993;11(6):897-906. doi:10.1002/jor.1100110617
International Journal of Nanomedicine

\section{Publish your work in this journal}

The International Journal of Nanomedicine is an international, peerreviewed journal focusing on the application of nanotechnology in diagnostics, therapeutics, and drug delivery systems throughout the biomedical field. This journal is indexed on PubMed Central, MedLine, CAS, SciSearch ${ }^{\mathbb{B}}$, Current Contents ${ }^{\mathbb{B}} /$ Clinical Medicine, $^{2}$
Dovepress

Journal Citation Reports/Science Edition, EMBase, Scopus and the Elsevier Bibliographic databases. The manuscript management system is completely online and includes a very quick and fair peer-review system, which is all easy to use. Visit http://www.dovepress.com/ testimonials.php to read real quotes from published authors.

Submit your manuscript here: https://www.dovepress.com/international-journal-of-nanomedicine-journal 